\title{
Applying structuralist semiotics to brand image research
}

\author{
George Rossolatos ${ }^{1}$ \\ PhD Researcher, University of Kassel, \\ Kassel, Germany
}

\begin{abstract}
The aim of this paper is to display a conceptual and methodological framework for brand image research by drawing on the discipline of structuralist semiotics. Upon a critical review of existing research from key authors in the brand semiotics literature and through an engagement with the concept of brand image as formulated by key authors in the marketing literature, a semiotic model is furnished for the formation of brand image and brand identity. By drawing on the structuration process of brand image along the three major strata in a brand's signification trajectory, and the key operations of reduction, redundancy, recurrence, isotopy, homologation, I focus more narrowly on how the chaining [enchainement] of elements from the three strata is effected with view to addressing how brand image may be operationalised in structuralist semiotic terms vis a vis a brand's intended positioning, how it may be linked to a brand's advertising discourse and how the conceptual framework may yield a platform for ongoing brand image analysis and management.
\end{abstract}

\section{Introduction}

Brand image is a heavily researched topic in the marketing literature. In contradistinction to marketing semiotic approaches to brand image creation that do not assume as their point of departure conceptual and methodological frameworks embedded in the marketing literature, my contention is that a proper brand semiotic approach should engage critically with existing approaches in the marketing literature, alongside perspectives that have been offered within the semiotic discipline.

This paper assumes as a vantage point the fundamental principles of brand image creation by comparing and contrasting dominant perspectives in the marketing literature. Then it proceeds with an overview of key semiotic approaches to brand image creation, from a structuralist semiotic point of view, while pointing to areas in which they attain to complement existing marketing approaches. By recourse to discerned limitations in these semiotic approaches an attempt is made to fill in some of the conceptual and methodological gaps. The contribution of structuralist semiotics to brand image research is highlighted by exemplifying the proposed

\footnotetext{
1 grosolatos123@myway.com
} 
methodological guidelines in terms of advertising communication as a key source of brand image generation.

\section{Marketing approaches to brand image}

In this section key branding models in the relevant literature will be reviewed and fundamental branding terms will be defined. In particular, the issues of what is a brand, how it is formed, what is brand image and brand values, why brand identity as genetic programme is important in maintaining long term brand associations and how the different layers making up brand meaning may be identified and mapped out will be explored and critically discussed. Since the point of departure is marketing discourse, semiotic interventions will be kept at a minimum. Occasional semiotic reflections in the course of displaying branding approaches that stem from the marketing literature will pave the way for making sense not only of how a semiotic approach may yield different perspectives on the same branding phenomena, but how the very selection of a semiotic paradigm reframes radically the phenomena under scrutiny.

There are two major types of assets that generate value for a company, viz. tangible assets, such as buildings and manufacturing plants and intangible assets, such as brands and research and development know-how. «Brands are powerful entities because they blend functional, performance-based values with emotional values» (De Chernatony 2006: 5). «Brands are intangible assets that produce added benefits for the business» (Kapferer 2008: 9). Examples of functional values include «security, convenience, simplicity» (De Chernatony 2006: 6), whereas examples of emotional values include «friendliness, conservatism, independence» (idem). «A brand represents a dynamic interface between an organization's actions and customers' interpretations» (ibid: 8). Davidson (in De Chernatony 2006: 11) draws a sharper distinction between visible and invisible brand elements, which is rendered metaphorically in the form of an iceberg, whose visible components consist of name and logo, whereas its invisible components consist of its values and culture.

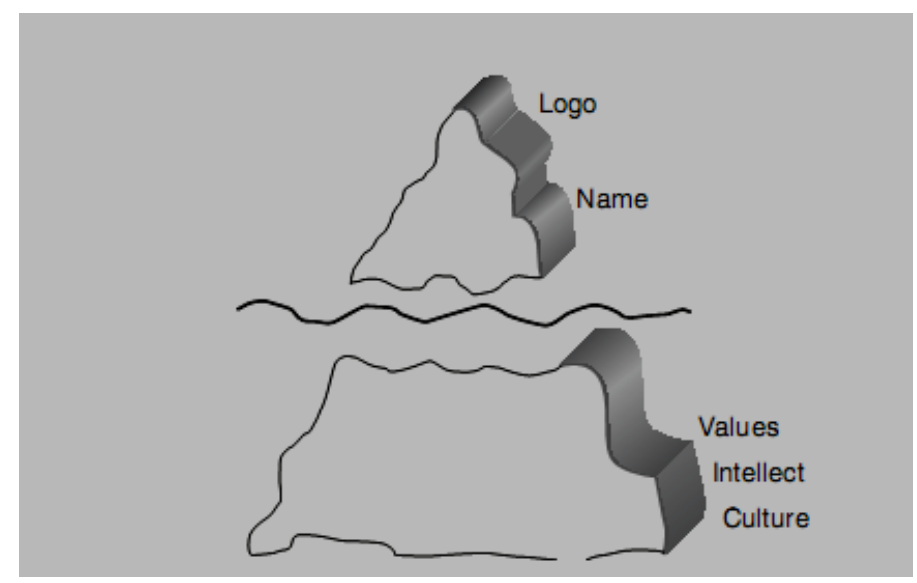

Figure 1: The branding iceberg (De Chernatony 2011: 11) 
As name/logo, a brand constitutes a trademark. «A trademark is any sign capable of being represented graphically, that is capable of distinguishing one organization's goods or services from another» (ibid: 13). A trademark may consist of various types of signs, of visual, verbal, aural modality, such as words, letters, numbers, symbols, shapes, drawings, unique sound compositions. Furthermore, the visible part of the iceberg includes any signs that come to be associated with a brand through time in the context of brand communications, such as particular branded characters, anthropomorphic animals, cartoons, actors, jingles, unique colors/typefaces, but also unique ways of ordering and arranging elements.

The branding challenge rests with correctly identifying and relating the two parts of the iceberg, that is elements of the visible structure with concepts/values of the invisible structure, as well as effecting a transition from the commodity that is laden with functional values to that of a branded or, as it is called in the marketing literature, an augmented product, laden with intangible added values. "Added value is a relative concept that enables customers to make a purchase on the basis of superiority over competing brands. It is about recognizing how new clusters of benefits from the brand enable customers to have greater gains relative to smaller increases in sacrifices (e.g. money, search time, etc.)» (De Chernatony 2006: 45).

This transition from the one stratum of the iceberg to the other constitutes a multi-step transformation, starting with visible brand components and ending with image associations and brand values. These associations, according to De Chernatony, must be relevant and sustainable.

Brand image attributes are customarily represented in marketing discourse through the metaphor of brand personality, which consists in ascribing an anthropomorphic structure to a brand. The correspondence of a brand personality with actual consumers'/ brand users' personalities has given rise to the so-called brand/self congruence hypothesis (Birdwell 1968; Parker 2009; Solomon et al 2006; Sirgy 1982). «By using the metaphor of the brand as a personality, manifest sometimes through a celebrity in brand advertisements, customers find it much easier to appreciate the emotional values of the brand» (De Chernatony 2006: 40).

The cluster of image attributes a brand wishes to project, by virtue of which it attains to carve a distinctive territory in the market wherein it competes, constitutes its intended positioning. The level of congruence of these attributes with what is esteemed by the consumer segment(s) that lie at the receiving end of the communication spectrum constitutes a brand's actual positioning. "It is imperative to recognize that while marketers instigate the branding process (branding as an input), it is the buyer or the user who forms a mental vision of the brand (branding as an output), which may be different from the intended marketing thrust» (De Chernatony and McDonald 2003: 24).

«Positioning is not what you do to a product. Positioning is what you do to the mind of the prospect. That is, you position the product in the mind of the prospect» (Ries and Trout 2000: 3 ). But positioning is also a comparative concept, designating the demarcation of a distinctive space with reference to other brands in a given category and a set of characteristics making up the target-market against which it is positioned. Just like value systems in general, brands as constellations of value evolve, thus their positioning is dynamic and must be constantly 
monitored against its saliency, differentiation, relative appeal. Thus, a demand for a coherent brand promise as consistent positioning is confronted with a dynamic market reality, which occasionally mandates that a brand repositions itself.

«Repositioning is how you adjust perceptions, whether those perceptions are about you or about your competition» (Trout 2010:10). Repositioning is an arduous and time-consuming endeavor and it does not occur overnight, insofar as it consists in replacing an existing nexus of values, functional and image attributes, benefits and associations stored in consumers' memory with a new one. The same holds for brand extensions, brand-stretching and diversification. In such cases a mother or umbrella brand proliferates alongside (i) different product/service categories through a logic of diversification (eg. Virgin, EasyJet) (ii) different variations in the same product category (eg. different Cadbury chocolate bar flavors, formats, sizes, packages) (iii) different brand promises, but with the same brand offering, for different consumer segments (eg. different perceptions of Nokia among men/women, 18-24/25-34 yrs old, business travelers/students and any other possible bases of segmentation).

Positioning concerns essentially the nexus of associations about a brand in consumer memory that makes up a battery of brand image attributes. As an ensemble these attributes constitute what is called brand image. Brand image may be further distribguished into category image, concerning associations about a product/service category in total and a specific brand's image. From a consumer based perspective, the associations most eminently related with a given product category constitute key perceptual value drivers (or critical success factorsCSFs). By benchmarking a particular brand's performance against the category's perceptual drivers, one may discern a brand's points of differentiation and points of parity. Points of differentiation contribute to carving a USP (unique selling proposition), the successful maintenance of which leads to a sustainable competitive advantage (cf. Keller 2008: 117).

Based on which value territories a brand intends to position itself, a distinction must be drawn between core and peripheral values. «A brand's core values are those values that the brand will always uphold, regardless of environmental change, and which will always be a central characteristic of the brand. By contrast, peripheral values are secondary values that are less important to the brand and which can be deleted or augmented» (De Chernatony 2006: 122). Core values make up a brand's essence. From a more holistic perspective, brand essence consists of a pyramid-like structure, encompassing attributes, benefits, values and the metaphorically projected brand personality as their synthesis. 


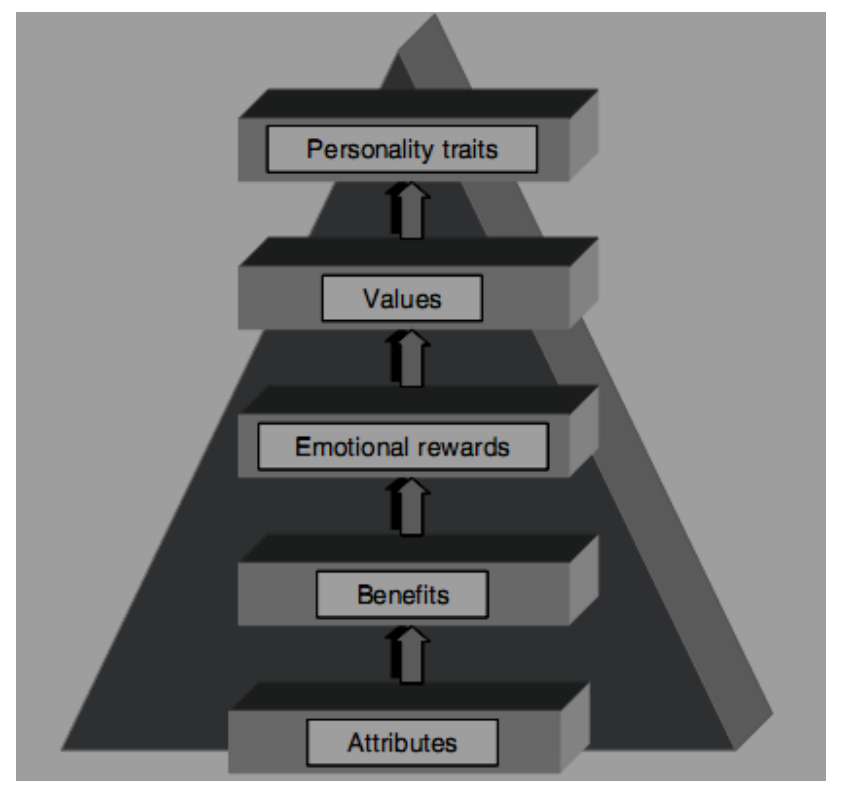

Figure 2: The brand essence pyramid (De Chernatony 2006: 226; also see Kapferer 2008; 34; Light and Kiddon 2009: 78-80)

The brand essence pyramid is a way of conceptualizing coherently the key aspects involved in a new brand (and not just product) development process insofar as it delineates the steps whereby product attributes are transformed into consumer benefits, which give rise to emotional rewards. In turn, emotional rewards are transformed into values in the form of an axiological framework. Values, once projected onto and recognized in the brand assume the form of brand personality traits, which are reflected in brand image attributes. The pathways whereby the layers of the pyramid interlock may be established inferentially through a laddering approach (see Kapferer 2008: 193). De Chernatony (2006: 227) suggests the employment of three «ladders» as a process of establishing the progressive ascent from attributes to personality traits, for each of the (up to) three key attributes making up a brand's core essence (cf. above on core vs peripheral values), obviously inspired by classical positioning theory (i.e. Ries and Trout) according to whom differential positioning should be based on no more than three distinctive attributes or properties.

The narrative that brings together the components of the pyramid in a short and concise manner (usually no more than one page long) constitutes the brand promise (also occasionally called brand positioning statement or brand mission statement). I shall call this narrative henceforth the master brand narrative, which functions as the conceptual backdrop behind an advertising concept, which in turn underpins an advertising script. The aim of a master brand narrative is to flesh out a distinctive brand positioning, which reflects a brand identity. Brand identity is not an unproblematic concept, since it points to something unaltered over time. Is brand identity feasible or is it just a heuristic concept? If it is feasible, how is it maintained over time and what determinants affect its uniformity?

Brand identity is not about repeating the same message over and over, but about maintaining a signification kernel throughout variable communicative manifestations. It is about the maintenance of identity through difference or the repetition of the master brand narrative 
through different customized brand narratives. The master brand narrative manifests the underlying depth grammar of a brand, whereas individual brand narratives constitute a brand's multifarious manifestations. As depth grammar a brand consists of immutable elements and a unique syntax whereby these elements are combined or its unique combinatorial rationale as brand code. The more carefully crafted the less easy it is to copy a brand's depth grammar insofar as it is cloaked through various transformations. Thus, maintenance of brand identity must also be coupled with a surface grammar and a transformational rationale whereby the master brand narrative is uniquely anchored in distinctive surface brand narratives.

As a precursor to the brand essence pyramid, Hollis et al (1996) forged the Brand Dynamics Pyramid, consisting of five identifiable steps in building a relationship of brand loyalty (presence, relevance, performance, advantage, bonding), which later evolved into the WPP patented branding model Brand Z (cf. Kotler and Keller 2006: 280) .

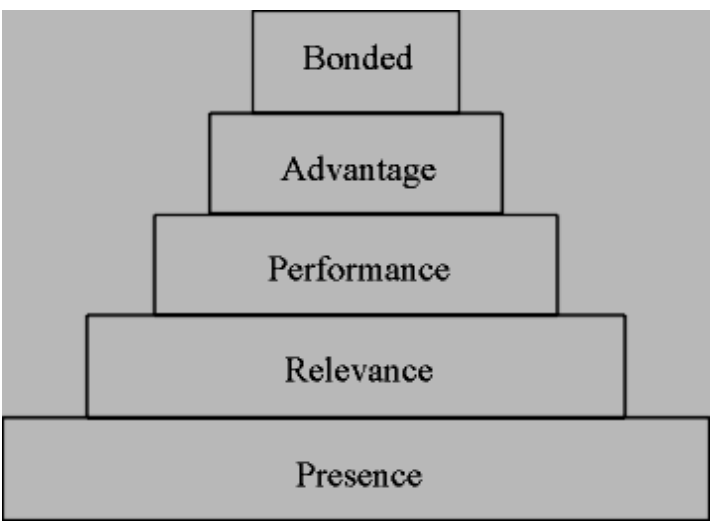

Figure 3: The brand dynamics pyramid (Hollis et al 1996; also see Hollis et al 2009 and Hollis 2008: 35-46)

Another metaphorical mode of portraying the coherence amongst the various strata and elements making up a brand is Kapferer's Brand Identity Prism. Its key point of differentiation from the brand essence pyramid (Figure 2) consists in its more inclusive character as regards brand mix elements, such as self-image and culture, as well as in an explicit portrayal of brand related aspects that were implicit in the brand essence pyramid. 


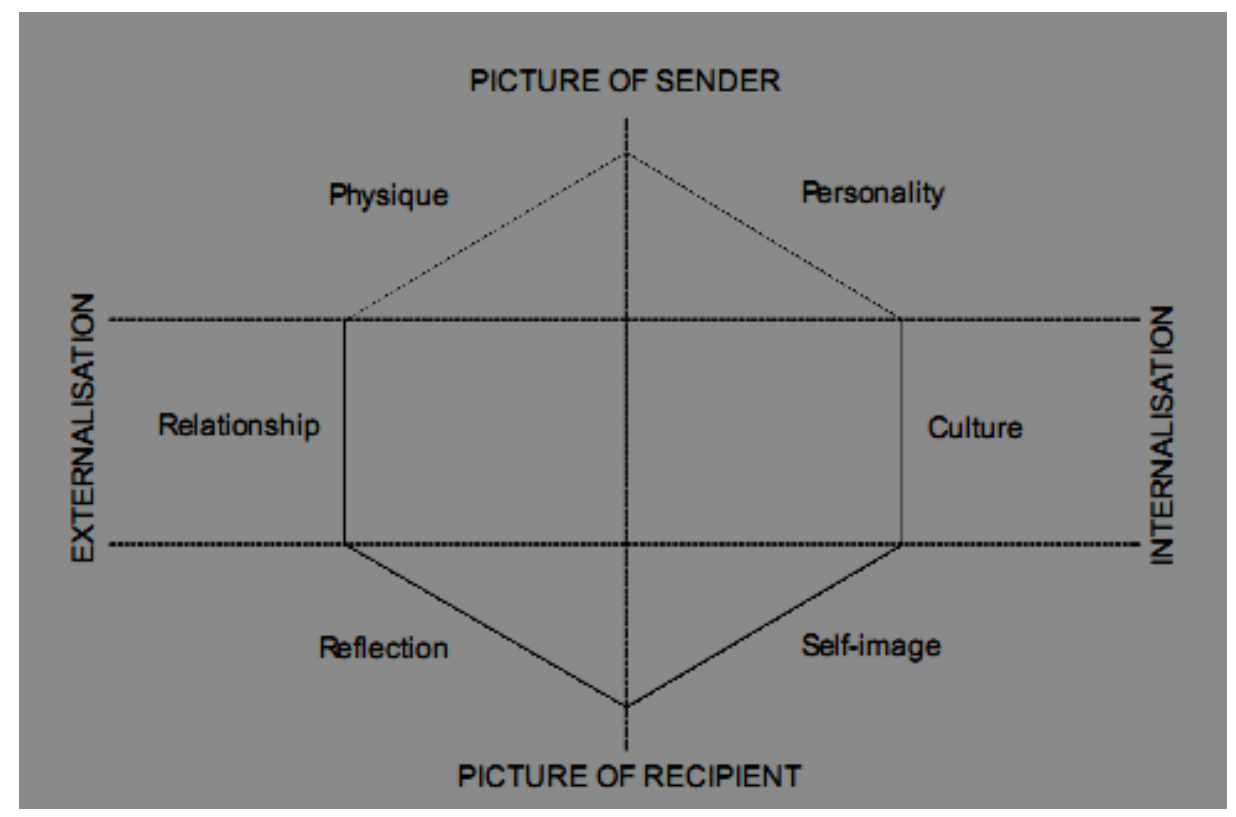

Figure 4: The Brand Identity Prism (Kapferer 2008: 183)

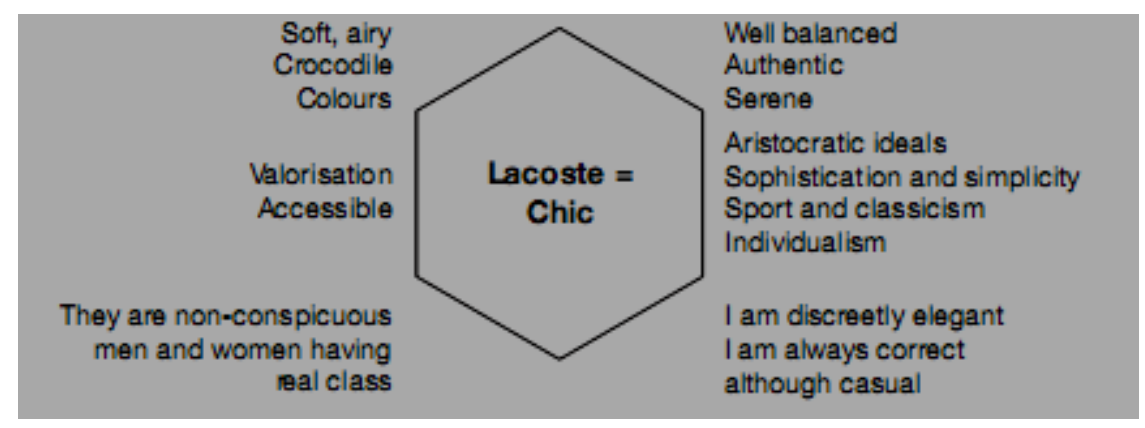

Figure 5: Applied Brand Identity Prism (Kapferer 2008: 188)

Physique refers to tangible elements or product attributes, personality to brand personality as previously defined, culture to a brand's values, relationship to «the mode of conduct that most identifies the brand» (Kapferer 2008: 185), qualified in terms of what I shall later call from a semiotic point of view the relation between manifest (logo, symbols, advertising cues or elements of a brand's plane of expression) and depth structures (brand image attributes or the plane of content) of signification. I deem that relationship is a key structural element, whose significance will be laid out extensively from a semiotic point of view, insofar as it points not only to elements making up a brand, but even more fundamentally, to the mode of elements' relatedness or a brand's combinatory logic. From a structuralist point of view relationship as such is not a component of a structure, but a combinatorial rule or a brand syntax.

Continuing with Kapferer's Brand Identity Prism model, reflection refers to the userpersonality projected by a brand as perceived by distinctive consumer segments and finally, self-image to «a target's own internal mirror» (ibid:186), which is more or less a deflection of user-personality. Brand Prism takes into account both senders' (or brand owners') and receivers' (or target audiences') perspectives by inserting the branding process in a 
communicative trajectory, while portraying the two interdependent and mutually reflecting facets of intended and received positioning.

From a terminological point of view, it is also quite crucial to notice that «identity reflects the different facets of brand long-term singularity and attractiveness» (ibid: 187). Identity is a multifaceted, dynamic concept that crystallizes over time against the backdrop of a long-term strategic orientation. Brand identity is not just a list of words alongside different dimensions stringed on a piece of paper as a static snapshot of a brand promise. It is an evolving entity, whose evolution may be mapped out on conceptual platforms such as the Brand Identity prism. Equally importantly, the notion of brand identity points to the self-referential rationale of a brand's structure as a system of inter-related attributes, benefits and values or to the fact that «the truth of a brand lies within itself» (ibid: 192). However, this coherentist outlook towards a brand's essence does not imply that it is cut off from a wider value-system making up a culture. «A strong bran is always the product of a certain culture, hence of a set of values which it chooses to represent» (idem). A crucial term that is lurking in the background at this juncture, is that of «cultural codes». The notion of code is of fundamental operative value not only for understanding the dynamic interplay between brand values and culture, but also as the open horizon of semiosis that caters for a brand's long term sustainability. "Code» as culture is accounted for in Kapferer's version of the brand pyramid, that is portrayed in Figure 6:

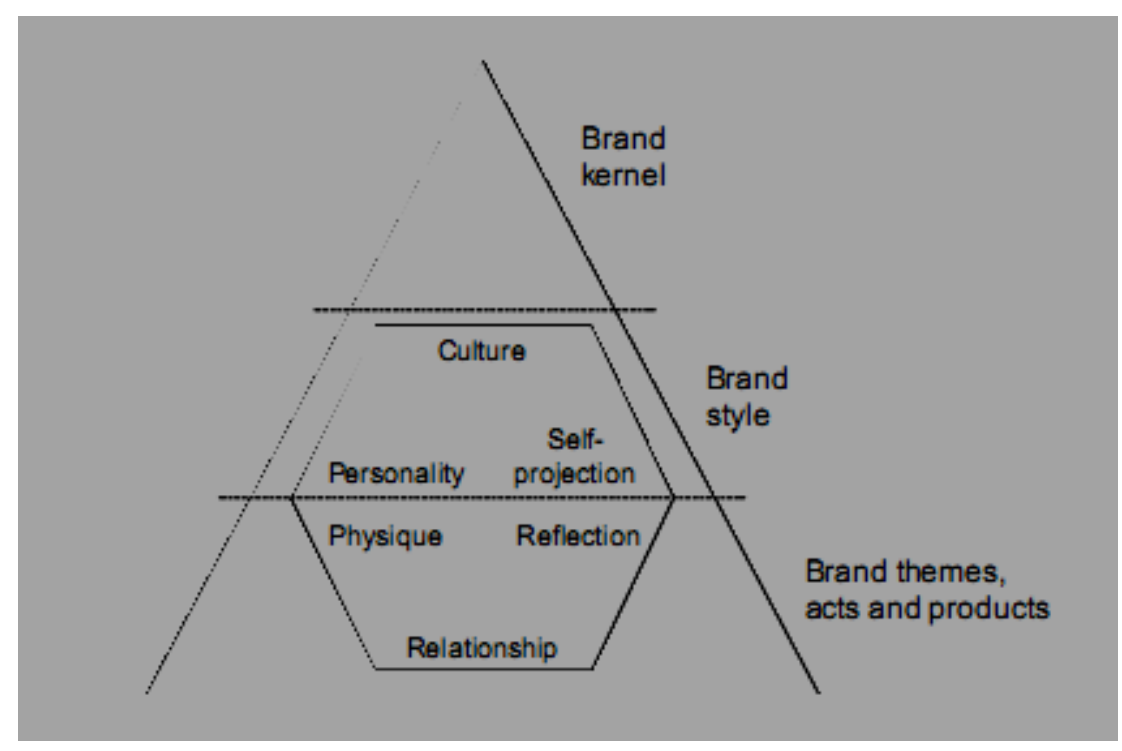

Figure 6: Kapferer's brand pyramid (2008: 291)

«At the top of the pyramid is the kernel of the brand, the source of its identity. It must be known because it imparts coherence and consistency. The base of the pyramid are the themes: it is the tier of communication concepts and the product's positioning, of the promises linked to the latter. The middle level relates to the stylistic code, how the brand talks and which images it uses. It is through his or her style that an author (the brand) writes the theme and describes him- or herself as a brand. It is the style that leaves a mark» (2008: 290). The notion 
of code as a brand's stylistic elements is essential, but very restrictive in terms of the importance of the notion of Code for branding. By restricting the source of the notion of Code not only crucial aspects in a brand's master narrative remain underexplored, but the very driving force of a wider cultural context and its dialectical relationship with a brand's constitution as such is understated. Irrespective of whether this approach to the Brand Identity Prism reflects from a holistic perspective the shaping forces that are operative in a branding process or remains wanting, its merits lie in identifying brand identity as a multi-layered concept.

De Chernatony and McDonald attribute a more all-encompassing role to the notion of Code in their branding system, while stressing that « brands are part of the culture of a society and as the culture changes so they need to be updated» (2003: 129). However, despite the descriptive value of the links between brand and cultural codes, the notion is not operationalized with view to yielding an account of how the dynamic between these two codes (ie brand and culture) develops over time.

Keller yields a more consumer-centric conceptual model of brand building, compared to the Brand Essence Pyramid and The Brand Identity Prism, that of Consumer Knowledge Structure. The key point of differentiation compared to the aforementioned models consists in adding emphasis to brand-related consumer associations, which, as will be shown in due course, constitute a central concept and formative perceptual mechanism in building and maintaining a brand image structure. «Brand knowledge can be conceptualized in terms of a brand node in memory with brand associations, varying in strength, connected to it» (Keller 2008: 87) and portrayed in the following fashion: 


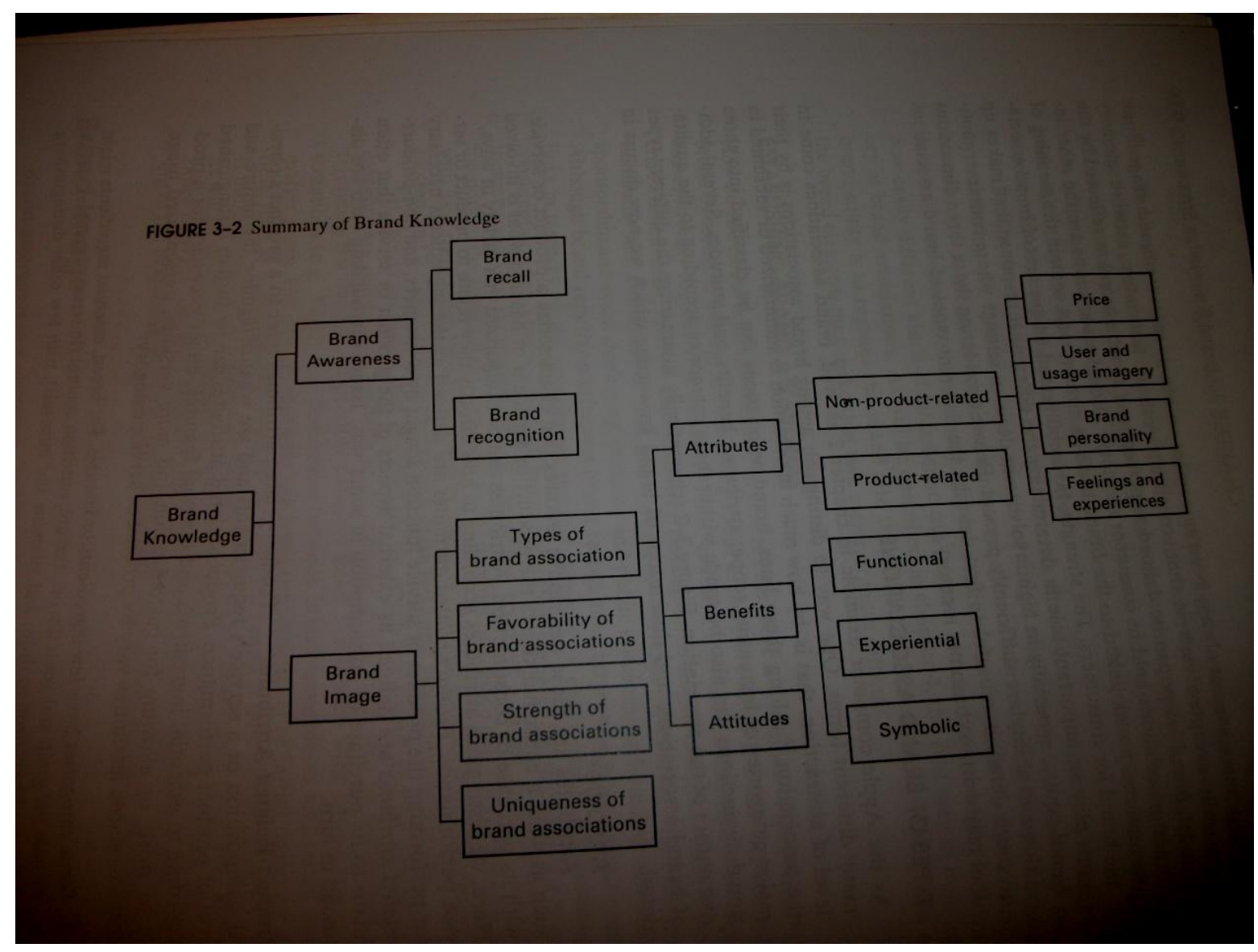

Figure 7: Keller's brand knowledge structure (Keller 2008: 94)

Keller's approach is structuralist in essence, from a semiotic point of view, even though not explicitly formulated as such. It emphasizes relations among elements in a brand system inasmuch as it outlines the distinctive value of the system's structural components. This model may be enriched from a semiotic point of view, primarily through a qualification of the various levels and modes of signification of brand image attributes, as will be shown in due course.

Let us now proceed with defining the components of the brand knowledge structure, while pointing out their relative structural value, as well as the way they interrelate and interact with view to yielding perceived added value.

Brand knowledge is fundamentally a function of brand awareness and brand image. Brand awareness is a threshold perceptual determinant of brand value and refers to "consumers' ability to identify the brand» (Keller 2008: 87). Brand recall relates to «consumers' ability to retrieve the brand from memory» (ibid: 88 ) when given a relevant cue, such as the product category's name. Brand recognition refers to the level of making purchase decisions when the brand is present. Another way of differentiating between modes of brand awareness is by drawing a distinction between aided and unaided brand recall. High levels of unaided brand recall, that is mentioning a brand name while being presented only with the product category as a cue, as well as the order of recall of brands, are indicative of the relative salience or 
pertinence of a brand in a category repertoire. The relative standing of a brand in the order of unaidedly recalled brands in a given product category is manifested as a brand's top-of-mind awareness. Brand awareness, conceived of independently of brand image perceptions is a necessary, but by no means sufficient condition for differentiating a brand. «Brand image can be defined as perceptions about a brand, as reflected by the brand associations held in consumer memory» (Keller 2008: 93). Brand associations contain the meaning of a brand, hence their value is instrumental as determinants of brand signification. Brand association may be further classified into three categories, viz. attributes, benefits and attitudes.

«Attributes are those descriptive features that characterize a product or service, such as what a consumer thinks the product or service is or has and what is involved with its purchase or consumption» (Keller 2008: 93) and may be further distinguished into product and nonproduct related. «Product-related attributes are defined as the ingredients necessary for performing the product or service function sought by consumers and non-product related attributes are defined as external aspects of the product or service that often relate to its purchase or consumption in some way» (idem).

The distinction between product and non-product related attributes is crucial from a semiotic point of view. The latter point to the brand's highly motivational status, in semiotic terms. There is nothing inherent in the brand determining the relationship between two sets of attributes. Non-product related attributes refer to «all kinds of associations that can become linked to the brand that do not directly relate to product performance» (ibid: 95) or, in semiotic terms, elements of the plane of content. This is what Baudrillard calls general commutation, which is an overarching principle in the language of brands viz. that any element of the plane of expression may potentially be correlated with any element of the plane of content. An attestation of this general commutability canon is the classic Coca-Cola slogan «things go better with Coke».

Non-product related attributes are classified into five types, viz. «price, user imagery (i.e. what type of person uses the product or service or who is the ideal user), usage imagery (i.e. where and under what types of situations the product or service is used), feelings and experiences and brand personality» (idem). In greater detail, non-product related associations arise both from direct contact with and usage of a brand, as well as from the imagery projected through brand communications.

User imagery characteristics may refer to any traits pertaining to the demographic background of the brand user (i.e. gender, socioeconomic class), psychographic/lifestyle traits (i.e. values autonomy in decision-making and is indoorsey vs outgoing), Feelings and experiences include feelings towards the brand generated through impersonal or one-to-many brand communications (i.e. TV, radio, outdoor, internet static banners), a brand's experiential events, such as roadshows, club-events, cinema promotions, but also through one-to-one brand communications (i.e. customized email marketing, social media, brand forums, CRM activities). 
Brand personality refers to a personification of a brand, that is the ascription of human attributes and is built primarily through brand communications.

Benefits «are the personal value and meaning that consumers attach to product or service attributes» (Keller 2008: 99). Keller draws a sharper distinction between functional, symbolic and experiential benefits. Functional benefits correspond to product-related attributes, hence their relationship is more monosemic and less abstract. The relationship between attributes and benefits becomes polysemous once we turn to symbolic and experiential benefits. «Symbolic benefits relate to underlying needs for social approval or personal expression and outer-directed self-esteem» (idem). Symbolic benefits have been associated in the consumer research literature with the symbolic self, which denotes complementing one's notion of selfhood by identifying with the symbolic properties with which an object or brand is invested. By virtue of an ideational transfer of these values embedded in the product to the self the act of symbolic consumption is effected. Experiential benefits refer to the feelings arising from brand usage, relating to either product or non-product related attributes.

Last, but not least, brand attitudes reflect «consumers" overall evaluation of a brand» (Keller 2008: 100), and form the basis for actual consumptive behavior or brand choice. Brand related attitudes constitute generic background expectations and determine to a certain extent the receptivity to brand related cues, including advertising cues.

Keller's brand knowledge structure, by virtue of positing brand related associations at the very heart of a brand's structure, affords to yield a comprehensive account of the interrelations amongst attributes, benefits and attitudes, but also to shift the focal point of building and managing a brand from internal considerations pertaining to the choice of brand elements to the end result of this choice, that is the formation of strong, favorable and unique brand associations on behalf of consumers.

However, in order to yield a more comprehensive account of the interrelationships amongst attributes, benefits and attitudes, both with regard to resulting associations, as well as the elements used for creating such associations, one needs an encompassing theory of signification, which may be furnished by recourse to structuralist semiotics and more specifically by recourse to Greimas's trajectory of signification. In the ensuing section Greimas's influence on Floch and Semprini's brand semiotic approaches will be discussed, alongside other perspectives in the struturalist stream of brand semiotics .

\section{Structuralist semiotic approaches to branding}

In terms of the contribution of semiotics in branding theory and applied research De Chernatony and McDonald (2003: 146-158) recognize that the symbolic dimension of brands or how they function as cultural signs may be unearthed with the import of the science of semiotics. "If marketers are able to identify the rules of meaning that consumers have devised to encode and decode symbolic communication, they can make better use of advertising, 
design and packaging» (ibid: 145). Brand symbolism is certainly a key area where semiotics may contribute, but not the only one. What is termed «symbolic consumption» in the marketing literature, from a semiotic point of view consists in a multifaceted phenomenon, also including, according to Greimas and Floch, semi-symbolic systems, but also imaginary constructs, with fluid symbolic boundaries. At the end of the day, as Greimas contends, a structure aims at organizing the imaginary. A structure is not necessarily a strictly coded system and is not exhausted in a strictly symbolic relationship between signifier and signified. As Eco has repeatedly demonstrated, there are various levels of codedness in a sign system and as Groupe $\mu$, Sonesson, Hebert, Rastier, Barthes among others, have demonstrated there are various ways of organizing a sign-system (comprising multimodal signs), in terms of syntagmatic ordering, as well as the operations involved in the rhetorical transformations of signification. The usefulness of semiotics lies both in furnishing a typological classification of brands as signs, which is mostly the province of Peircean semiotics, as well as a conceptual and methodological platform for designing and managing brands as sign systems, which is mainly the province of structuralist semiotics.

\subsection{Floch's brand semiotics}

Floch pioneered in the application of Greimasian structuralist semiotics in marketing theory and research. His main work Marketing Semiotics that exemplifies his approach, which is complemented by Visual Identities, even though not furnishing a coherent branding theory, is interspersed with insightful conceptual and methodological remarks, borne out of his active involvement in applied semiotic marketing research. In this section an attempt will be made at reconstructing the most relevant branding arguments in a concise conceptual framework.

According to Floch, the first principle is that «the thrust of semiotics is the description of conditions pertaining to the production and apprehension of meaning» (Floch 2001: 2), in line with Greimas. The second principle (the so-called immanence principle, in line with Greimas and Hjelmslev) is that «semioticians look closely at the system of relations formed by the invariants $^{2}$ of these productions and apprehensions of meaning by analyzing specific components known as signs» (idem). «Semiotics seeks to work from texts, to work on and in that very place where signs signify» (ibid: 3 ). Floch,, in line with Greimas's' system, adopts the model of generative trajectory of signification, which consists in a topography of relations, starting with deep levels of signification and ending with the manifest text or advertising stimuli. «Like a word, an advertising concept constitutes only the small,visible tip of an iceberg of meaning» (ibid: 6). The generative trajectory of signification is portrayed in Figure 13:

\footnotetext{
${ }^{2}$ The same principle holds in the case of film semiotics. As Buckland (2004: 6) observes «Film semioticians define specificity not in terms of film's invariant surface (immediately perceptible) traits, but of its underlying (nonperceptible and non-manifest) system of invariant traits", even though invariance from a structuralist point of view concerns both planes of expression and content and not just the plane of content as Buckland holds.
} 


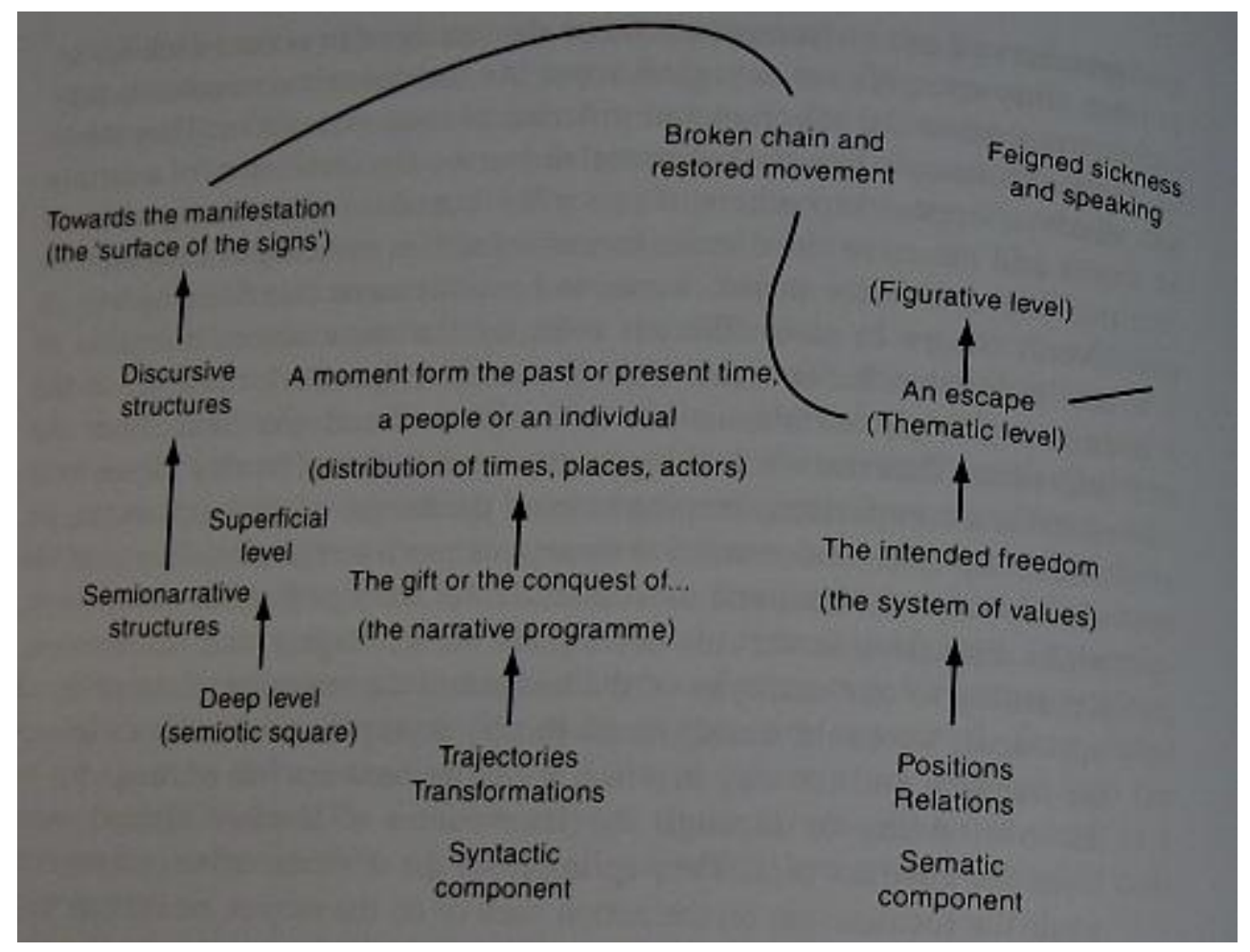

Figure 13: The generative trajectory of signification (ibid: 114)

The above rendition by Floch of Greimas's generative trajectory of signification constitutes the blueprint for the organization of brand signification. Floch;s rendition focuses on semionarrative and discursive structures, at the expense of the depth level of signification, which is deemed to be exhausted within the province of the semiotic square.

«The deep level of the semio-narrative structure, its superficial level and the discursive structures have two slopes or sides that reflect the two components of all grammars, a syntactic component (or what is derived from a logic of the trajectories) and a semantic component (or what is derived from a logic of the positions and values)» (ibid: 113).

Based on the generative trajectory of signification a brand acquires meaning by passing through different levels or structures, viz. depth structures, semio-narrative structures and discursive structures. «Semio-narrative structures consist of the entire set of virtualities the enunciating subject has at its hand; It is that supply of values and programmes of action from which he or she can draw in order to tell his or her story or speak of any given topic» (ibid: 112-113).

Discursive structures «correspond to the selection and ordering of these virtualities. They relate to the choice of a specific referential universe» (ibid: 113).

Another key Greimasian concept that pertains to semio-narrative structures and that was operationalised by Floch in his brand exploratory research is that of narrative schema. The narrative schema is a concept that attempts to encapsulate a narrative as an ordered sequence of interrelated formal episodes. The ordering does not correspond to the succession of events at the surface of a narrative, which was Propp's original conception of a narrative schema, 
hence it is not only of a syntagmatic nature, but also of a paradigmatic nature, insofar as the syntagmatic sequences are reordered based on paradigmatic units or dominant themes that cut across the syntagmas. «By conducting a critical reexamination of the Proppian functions in this fashion, the idea of a directed arrangement was substituted for the notion of simple succession; a narrative, then, was thought to be imbued with a meaning, a direction» (Floch $2001 ; 50$ ). The incidence of directionality as motivating principle behind the organization of a narrative schema is particularly relevant in the context of a brand master narrative, which is embedded in a highly motivated brand langue.

A major issue that surfaces, in my view, in Floch's attempt to put Greimas's narrative semiotics to branding practice concerns the direct migration of the metatheoretical concepts embedded therein to the reading of a brand's manifest discourse or its advertising texts, while not taking into account that the primary field of application of Greimas's narrative approach was the literary text and the inspiration behind the canonical narrative schema dwelt on the particular genre of the Russian folktale. Thus, narrative typologies such as 'hero' and 'opponent' are applied directly to the advertising text (and have been standardly applied until today to a plethora of structuralist semiotic advertising studies). Concomitantly, Floch's reading of advertising texts, rather than being selective with regard to the validity of Greimas;s narrative metatheory in the face of the particularities of the advertising text and its differences from literary works, amounts to its uncritical validation. Floch imports directly Greimas's narrative schema as consisting of four identifiable phases, viz. establishing a contract between sender and receiver of the text, the qualifying test or the acquisition of the ability to realize a narrative program by the sender, the decisive test or the carrying out of the program and finally the glorifying test that seeks to recognise whether the narrative program has been completed. Greimas attributes a set of modalities to the above phases, such as the epistemic modality, that is established in the qualifying test in terms of the sender's knowhow about the completion of the program.

On the one hand, this performance related modality may be established in a literary narrative cogently with regard to the literary work's internal structure on behalf of the receiver, as the choice of the receiver to accept the valorization of the object offered by the composer of the literary text does not have any material repercussions. However, in the case of consumer choice, opting for the acceptance of a mode of valorization of a brand as portrayed in an ad text has material repercussions, in terms of the monetary value involved in the act of exchange wherein the valorization is embedded, but also in terms of psychological value. In short, the sanction of an axiological framework established by a destinateur [sender] in a literary work is a risk free enterprise for the destinataire,[receiver], whereas in the case of the brand motivated ad text, risk is involved in terms of distinctive value territories.

On the other hand, the literary oeuvre is not necessarily motivated by a conceptual blueprint. Thematic isotopies may be discerned through a reconstruction of the narrative (as proposed by Barthes' code theory in S/Z), but this coding does not have to correspond to an a priori positioning blueprint. In the case of the ad text such a conceptual blueprint in terms of a brand positioning statement is a necessary condition. 
Furthermore, narrative structures are accompanied not only by narrative elements, but also by a transformational syntax that regulates the transitions among the states of being of the key actants involved in the narrative. The transformational syntax in the case of the ad text is greatly influenced by advertising style (i.e. humouristic advertising vs call to action). Styles of advertising execution correspond to the paradigmatic axis of a brand's discourse. Each style has its own mode of effecting a valorization of the object or a brand and hence its own narrative schema. Style also constitutes the context as corpus through which textual signification is interpretively possible, according to Rastier (2003). The text points inevitably to genre as intertext. In this respect, importing directly Propp's canonical narrative schema as adopted by Greimas and in turn by Floch to advertising analysis obfuscates the crucial difference between the ad and the literary text in terms of the sender's motivational structure, as well as the fact that the middle term for decoding ad texts does not rest with the corpus of the Russian folk-tales, but with distinctive genres or styles of advertising execution.

In order to illustrate the above tentative criticisms of Floch's application of structural semiotics to advertising, let us cite the following passage:

«literary works provide numerous examples of very different kinds of competence depending on the echainment, the process of acquiring the necessary modalities to implement a given programme of action. For instance, there are 'heroes' who already possess a 'being-able-to' and a 'knowing-how-to', but are not yet competent- they will not be capable of fulfilling their mission until they have acquired a 'wanting-to' or a 'having-to'... In this respect advertising provides a marvellous diversity of competence that is syntagmatically defined» (Floch 2001: 53-54; my emphases).

It is evident from the opening and closing premises of the above statement that Floch conflates the literary and advertising modes of discourse. The outcome of this precarious imbrication is that the three modalities that have been posited as integral to the carrying out of a narrative program that is embedded in a narrative schema and which attain to differentiate the actions of the actors in the literary oeuvre are assumed to be capable of conferring signification to the actions of the actors (if any) in an advertising text. But this is hardly the case insofar as (i) in an advertising text the omnipresent actantial subject behind the manifest actors is the brand, which is assumed by default to possess all three modalities (i.e. having to, being able to and knowing how to). Hence, Greimas's modalities do not attain to differentiate a brand's narrative, as they are supposed ex positio to be endemic in brand discourse (ii) as per the previous argument the competence of a brand that is instituted in the brand narrative is not only syntagmatically defined, but also paradigmatically determined, based on the selection of an advertising style, the transformative syntax of which determines the syntagmatic ordering of surface elements.

Wrapping up our argumentation, brand discourse varies markedly from literary discourse in terms of motivation and intentionality behind the text's manifest structure, as well as in terms of discursive style. Not taking into account the motivational structure of an ad text has repercussions alongside the generative trajectory. The invariant functions and characters that were discovered by Propp and adopted by Greimas may not be uncritically assumed as 
deductive principles for the semio-narrative reconstruction of an ad text ${ }^{3}$. The non universally applicable Proppian semio-narrative typology was vehemently emphasized by Rastier in his criticism against Greimas's uncritical adoption that appeared in Sens et Textualité. «His theoretical ambition is restricted by descriptive weakness: his universalism prevented him from discerning the specificity of texts, thus projecting the semiotic narrative schema as an a priori grid» (Rastier 1989: 69).

The impact of opting for each of the above approaches in the context of establishing brand coherence alongside the generative trajectory may be clarified by addressing the way Floch attempts to illustrate the usefulness of Propp's narrative functions in the advertising development in Chapter 3 of his book Marketing Semiotics (Floch 2001: 54-72).

The illustration draws on the actual case study concerning the bank brand Credit du Nord and its commissioning a project to a design agency for a new tagline (slogan) and a new logo. First, the case selected for illustrating the pertinence of narrative functions is completely different to the initial frame of discussion that aimed at establishing a relationship between the literary oeuvre and advertising discourse, as the case does not concern advertising, but logo and tagline, which are key brand properties, but may not be approached in isolation to brand discourse as deployed in advertising. Second, this divergence from the initial aim is further compounded by focusing on the interior space design of the bank's outlets. Third, the narrative function of 'helper' is dislocated from the semio-narrative stratum in the generative trajectory (which Floch reproduces in his book according to the Greimasian rationale) and conflated with a brand's depth grammar as a key seme, manifested in the tagline 'A big bank for a big region' (Floch 2001: 54). In this sense, 'helper' has nothing to do with the narrative function of 'helper', but with the adoption of /helper/ as a nuclear seme in the brand's semantic microuniverse. Fourth, Floch claims that the bank intended to position itself around the concept of 'clarity' and attempts to construct how clarity emerged through the elements of the aesthetic surface of the branches' interior design by recourse to a whole host of speculative remarks about the 'effects of sense' of pure surface structure elements, such as shapes, lighting, colors and their mode of combination. This reading that bypasses the strata of the generative trajectory constitutes a contradiction in terms on at least three levels: (i) on the level of Floch's line of argumentation in Chapter 3 that intends to clarify the adaptability of literary work narrative structures to the advertising text, a visual text is interpolated as exemplar (ii) on the level of assuming as point of departure the generative trajectory, an example is recruited that bypasses the strata of the trajectory; instead of demonstrating how brand signification or the intended nuclear seme of /clarity/ emerges through the three main levels of the trajectory (of which semio-narrative structures is the middle one) he jumps onto justifying how clarity emerges as an 'effet de sens' based on the syntagmatic ordering of visual stimuli or 'bricolage' (iii) by assuming (at least implicitly) as his point of departure not the generative trajectory, as deployed by Greimas and Courtes, but Greimas's later (1989 d) work on the semiotics of the figurative and plastic signs (in which case the collaboration of Floch was crucial), where the relative autonomy of the expression plane of the visual sign is

\footnotetext{
3 Let us note that Floch's import of Greimas's narrative typologies is still popular among current applications in advertising analysis. For example, see the Cillit Bang case study in Shairi and Tajbakhsh 2010.
} 
argued for, along with a call for bespoke 'reading grids' [grilles de lecture] for constructing semiotically signification as an 'effet de sens' based on the surface play of visual signs.

Floch's divergence from the generative trajectory of meaning and his increasing preoccupation with the production of signification as an effet de sens of surface structures became even more apparent in his later work Visual Identities. This transition makes sense in the context of Greimas's call for an alternative reading grid in the case of the plastic and figurative sign (cf. Greimas 1989 d), as a result of the particularities of the visual sign. In this direction he heralded Floch's work for furthering the project of structuralist semiotics in order to encompass the plastic sign. Whereas in his earlier work Greimas's main preoccupation rested with furnishing a descriptive metalanguage of deductive validity the semantic kernel of which would rest with a depth grammar, in his later work he turned to the other extreme and examined the extent to which signification is purely a matter of style or surface structures pertaining to the plane of expression. Floch describes this turn as follows:

«Style is generally defined as divergence or deviation. In such an approach style is conceived as an opening, a way of taking liberties with a norm located outside the work. This approach is essentially paradigmatic and normative [...] However, in an approach more concerned with the work itself and centered more on text than context, style can instead be defined as closure. And this closure is linked to the syntagmatic dimension of the work. Moreover, this approach which takes into account the internal recurrences and consistencies of the work is by no means normative. Rather, it is the approach associated with those stylisticians closest to semiotics, an approach that is intended as purely descriptive and is concerned above all with relationships internal to the work itself» (Floch 2000: 139).

The diversion from a canonical narrative schema as a set of normative requirements regulating meta-theoretically the internal coherence of a text towards style as an associative rationale of surface structure elements also marks a distinction between the deductive validity of a canonical narrative schema and style as heuristic mechanism for making sense of the mode of signification of figurative discourse and the visual text as against the literary narrative form. Yet, they are both embedded in figurative discursive forms.

The issue of the relative autonomy of surface discourse versus its dependency on depth structures is a vexed one. Semiotics may contribute to the analysis and interpretation of a surface text's organization and hence extrapolate rules for the maintenance of communicative consistency regarding the organization of advertising stimuli, albeit not dislocated from a brand's depth structure, not as master brand narrative embedded at the semio-narrative level, but as coherent brand identity resting with immutable brand image attributes as a brand's semantic micro-universe. What occasionally obfuscates the precedence of levels of analysis in the trajectory of signification is the circular interdependency of the depth and surface structures. Since the original inception of his multi-layered system in Sémantique Structurale (1966), Greimas rendered clear that depth and surface structures are mutually presupposing. A depth structure is the necessary condition for the existence of a surface structure, while a surface structure may not exist, structurally speaking, without a depth structure. Greimas also 
made it clear that one may start building a structuralist sign system either way, that is by starting from a surface structure or a depth structure.

His argumentation came under attack from scholars, such as Ricoeur (1989), in the face of his programmatic declarations in Sémantique Structurale, according to which the metalinguistic theory of structural semantics aims at yielding a deductively valid theory of signification. The attribution of deductive validity to his metalinguistic theory concerned the internal structural coherence of the posited concepts, hence the immanentist nature of structuralist semiotics and not the ability to predict extra-semiotic phenomena. For example, the typologies that make up a canonical narrative schema are canonical, precisely by virtue of their uniform recurrence in the context of a given corpus (certainly with variations). The structuralist backdrop allows for the establishment of a set of background expectations about the deployment of a narrative schema, within a given corpus of analysis, whence stems its deductive validity. The canonical narrative schema is of deductive validity because it places constraints on the probability of a narrative program's deployment in a specific direction. However, the canonical narrative schema was invested with deductive validity upon observation of patterned regularities in a given corpus. The source of the deductive model consists in uniform «inferential walks», employing Eco's eloquent metaphor, that is in successive inductive chainings of the deployment of individual narrative programs. A structuralist semiotic system is deductive by reference to a given corpus, which adds further credence to the aforementioned problematic direct transfer of the typologies embedded in a canonical narrative schema as borne out of the corpus of the Russian folk tale to advertising discourse. Moreover, this approach to the formation of a deductively valid canonical narrative schema affords to dispel Ricoeur's (1989) criticism against Greimas that «movement from one level to the other thus loses all its deductive nature. The complex interplay of these two requirements gives the whole enterprise the ambiguous appearance of reducing narrative to logic or of seeing narrative as a surpassing of logic. The actantial model consists in an ex post facto reconstruction and not in an a priori valid model».

Ricoeur's criticism may be applied to three different areas regarding Greimas's semiotic system.

First, it is applicable at the level of reducing figurative discourse to logical analysis, which concerns the transition from the mid-level semio-narrative structure to the depth level of the semiotic square (based on Du Sens I) and the elementary structure of signification or semic axis (based on Sémantique Structurale).This transition is of particular relevance for branding discourse insofar as a brand's langue indeed consists of an interplay between a logically coherent text (i.e. its positioning statement or master brand narrative), and figurative discourse (i.e. its advertising executions). In this instance, reduction of a brand's meaning through the redundancy of contextual sememes is indeed a prerequisite for maintaining a uniform brand identity, as will be displayed in section 5 .

Second, it concerns the circularity embedded in the notion of an a priori valid model. As Greimas contends, a semiotic trajectory may be constructed either bottom-up or top-down. The model is deductively valid insofar as irrespectively of whether semiotic (re)construction 
begins from the depth level or the surface level, the elements of the strata of the trajectory will be related in exactly the same fashion. Let us recall that relations among elements are of primary importance for structuralist semiotics, and not the elements themselves. A structural component may be semantically invested in various ways, but not the relations among components. It is the particular modes of relatedness that furnish brand coherence, and not the visual and verbal elements involved (or, at least, not primarily). This may be perceived as an over-statement and an underplaying of the importance of surface discourse elements, but it will become clearer by allusion to the key structuralist operations involved in building a brand's signification trajectory, as will be illustrated in section 5 .

As an extension of the second point, a structuralist system may be perceived as losing its deductive validity while moving, for example, from the surface to the depth level and vice versa, but this holds if we shift focus from modes of relatedness to individual signs. Certainly, a structuralist edifice may not be of predictive validity when attempting to determine why a depth structure's semic element is correlated with a manifest discourse's element, but, as already stressed, what is of primary importance in determining the deductive validity of a structuralist model is not individual components, but their mode of relatedness across strata. As will be illustrated in section 5, deductively valid structural coherence may be defined through a process of chaining multi-strata elements through key structuralist operations. Now, regarding the relationship between the reduction from the semio-narrative to the depth level of signification or the reduction of an actantial model to the logical square (where a concept as actant constitutes the initial term of a pair of contrariety that is the fundamental building block of the semiotic square) the following may be noted:

The reduction of a narrative to a semantic micro-universe is not equivalent to a reduction to logic, if by this statement Ricoeur means a filtering of narrative phenomena through formal logic. Greimas uses the eloquent term «logicosemantic simulacrum» as a proxy descriptor of the essence of the semiotic square. He borrows elements from formal logic, mainly basic notation of logical propositions, in an attempt to formalize the articulations of a semantic universe. He does not reduce structural semantics to formal logic. In fact, he lays claim repeatedly to the role of imagination and culture as key shaping forces of the semantic universe, he draws parallels between Freud's latent and manifest dream content when explaining the relationship between depth and manifest structures, while the starting point and key building block of his square is not logical opposition, but contrariety.

Contrariety involves both conventional and unconventional oppositions. In his dictionary he stresses explicitly that there are various kinds of logic (and informal logic counts among them) and structural semantics is a hybrid form. It does not surpass logic, rather it endorses logical fallacies as actantial probabilities. For example, if for traditional logic $\mathrm{P}$ and $-\mathrm{P}$ cannot hold true at the same time, from a propositional logic point of view, from a veridictory point of view (that is truth-telling) they both hold true at a plane of virtuality or virtual possibilities embedded in an actantial subject as virtual focal narrative point. Let us recall that the deployment of textuality is tantamount to the actualization of latent possibilities, as yet dormant at a plane of virtuality. At the beginning of a narrative an actantial subject is and is not predicated of a quality $\mathrm{X}$, something that must be verified from a veridictory point of 
view, while entering in a relationship of conjunction or disjunction with objects of desire and other subjects as antactants. The deductive character of the semio-narrative level does not rest with an unequivocal anticipation of surface narrative sequences, but with streamlining anticipation according to narrative probabilities of becoming or transformations among statesof-being through actantial doing, which may be discerned only once contextual elements of the surface discourse have been rendered redundant.

The above analysis raises the crucial issue of how one reaches the «logical» level starting from manifest discourse. Floch, by analyzing mostly print ads in the pharmaceutical category of psychotropic medication found that «this discourse had not been put together in a haphazard way, but according to a very specific encoding, the awareness of which enabled us to avoid taking for granted the incorporation of such details as the stable nature of a line, the dissymmetry of a form, the graphics of a design or the contrast of two values» (ibid: 75). By drawing on recurrent stylistic patterns Floch identified twelve distinctive visual categories in psychotropic drug advertising, viz. «clear vs dark», «shaded vs contrasting», «monochromatism vs polychromatism», «thin vs thick lines», «continuous vs discontinuous lines», «definite vs vague planes», «simple vs complex forms», «symmetrical vs disymmetrical forms», «single vs multiple forms», «high vs low», «layouts in conjunction vs layouts in disjunction», «pictorial vs graphic techniques». However, binarist pairs in the visual sign are not as clear-cut, as Sonesson argues: «Oppositions may be in absentia, or true oppositions, or in praesentia, or contrasts. Thus, in pictures there is no obvious equivalent to the system of (constitutive) oppositions present in the phonological and semantic organisations of verbal language» (Sonesson 2011:44).

These patterns constitute what Greimas would describe as a 'reading grid' of an expressive surface structure, an approach he pointed to in his article on the semiotics of the plastic sign, where a marked contrast to his earlier cross-generative trajectory construction of signification takes place.

Another point that merits raising in the context of the aforementioned argumentative procedure employed by Floch concerns the way valorization of the selected surface text of Credit du Nord emerges in the institution of the visual brand discourse (at least at the level of a $\operatorname{logo}$ ) and by implication the veridictory contract between brand as destinateur and consumers as destinataires. Floch postulates that by virtue of both the atomistic properties of the selected visual signs and their gestaltic interaction, the intended seme of clarity is successfully instituted and the axiological investment of the brand's identity with /clarity/ is veridictorily recognized by its prospective audience. This assumption does not takes into account the salience of the seme /clarity/ as intended key brand positioning element in the target audience's value system. In fact, Greimas's original contention is that valorization is instituted in the text, which in a sense is correct insofar as the way a brand assumes value depends on the effectiveness of its advertising texts. However, the valorization of an ad text also depends on the destinataire's existing value system, which the ad text aims to maintain or change. Thus, valorization is not just a case of the 'effet de sens' of an ad text, but also of its ability to change or maintain the destinataire's value system. 
Last, but not least, Floch assumes largely a non product category-wide approach in his semiotic analyses, while focusing on single brands irrespective of category specific value systems. This constrains significantly the validity of the output of his semiotic readings as by not importing a competitive outlook no frame of reference may be discerned, compared to which brand associations may be gauged as being unique, strong and favorable (bearing in mind the three defining criteria of brand associations, as posited by Keller).

Continuing with Floch's structuralist conceptual and methodological toolbox, a crucial concept imported to marketing semiotics from structural linguistics is the commutation test. «Commutation is the use of the relation of reciprocal presupposition between the expression plane and the content plane of a signifying set, between the signifier and the signified» (ibid: 8). «Invariants are correlates with mutual commutation and variants are correlates with mutual substitution» (Hjelmslev 1969: 74). It is only in the process of looking for such correspondences between the two planes of signification that «we begin to take note of the actual visual or auditory qualities that constitute the aesthetic of a given brand» (Floch 2001: 8-9), while a brand's signifying or textual structure emerges through distinguishing between core or invariant and peripheral or variable signifying elements. «This kind of coupling between the expression and content of a language constitutes a semi-symbolic system» (Floch 2001: 75; also see Floch 2000:46).

The distinction between invariant and variable elements of signification is also responsible for establishing different levels of semiotic pertinence or, as termed in the marketing literature, saliency. Pertinence is by no means a disinterested judgment. As Floch stresses, «documenting is in fact an act of construction and the choices that figure into it already represent a certain degree of pertinence» (ibid: 17). Semiotic pertinence is by no means exhausted in brand aesthetics, which pertain to the surface level of signification, yet whose contribution to the entire generative trajectory of signification is undoubtable. The commutation test is of paramount importance in maintaining brand coherence, but may not account for the need for consistency among variable surface ad textual manifestations.

The second key methodological tool operative in Floch's approach to marketing semiotics is the Greimasian semiotic square, a 'constitutive model' that can be used «for synchronic studies, that analyze historical situations, as well as diachronic ones that retrace historical evolutions» (ibid: 11). The starting point for the construction of a semiotic square is the identification of two contrary terms (i.e. good vs bad) that are related as opposite poles in a semantic axis. The initial terms of the square that constitute a relationship of contrariety are further extended to include their contradictory terms. «And there, too, are its 'interdefined' positions resulting from just three relations: (1) the relation of contrariety, represented by a horizontal line as illustrated at the beginning (2) the relation of contradiction, depicted as diagonal lines and corresponding to negation and (3) the relation of complementarity, a vertical line that corresponds to the operation of assertion» (ibid: 21-22).

The second task fulfilled by the semiotic square from a brand semiotic point of view is that soon after projecting relations of contradiction, contrariety and complementarity, the square can be transformed into four quadrants, where each quadrant stands for a distinctive consumer 
segment or consumer typology, based on that segment's valorization of the distinctive values represented by each quadrant.

The semiotic square from a communication point of view is complemented by the veridictory square and the veridictory contract. Floch furnishes examples of such squares, the first depicting the four travellers' typologies of the RATP (the Parisian underground) and the second depicting the values of Citroen, that emerged through a semiotic reading of brandrelated four year advertising materials (which analysis was later adopted as a universal axiological framework by Floch himself in Visual Identities- cf. 2000: 120 and by Semprini, as will be demonstrated in due course):

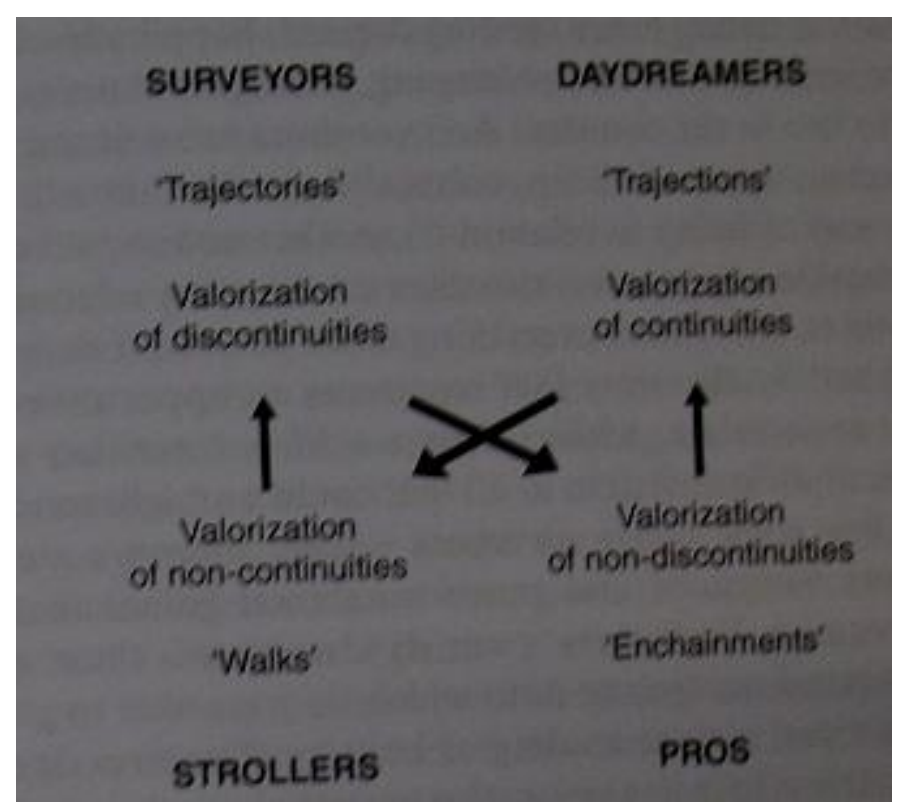

Figure 14: Typologies of RATP travellers projected on the semiotic square (ibid: 25) 


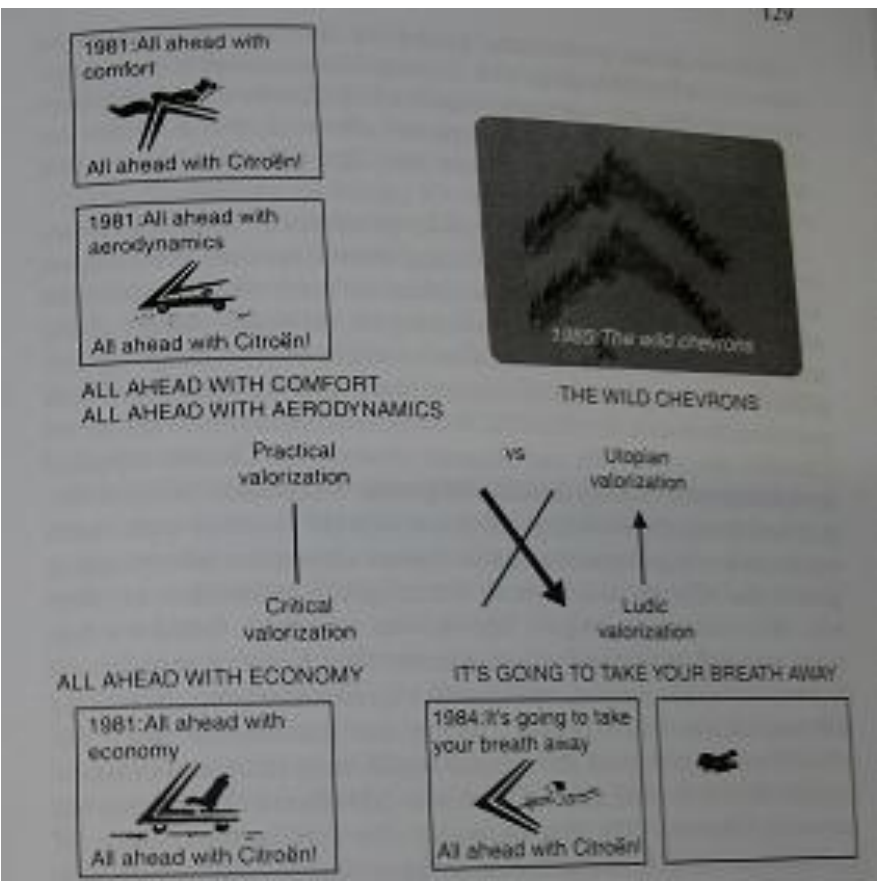

Figure 15: Citroen values as portrayed in its advertising between 1981 and 1985 (ibid: 129)

«The square is at once a static and a dynamic model» (idem). The purpose of a semiotic analysis is to map out «the network of relations organizing the semantic microuniverse» (ibid: 20) of a given product or service category. By obtaining a picture of what holds in a current market predicament the semiotician is capable of determining alternative brand positioning routes. Floch's applications of the semiotic square are undoubtedly exemplary. However, a critical dimension that is definitive of a brand's positioning and identity seems to slip from this applied perspective, viz. the incorporation of a competitive outlook. In both of the aforementioned cases Floch does not bring into the picture competitive brands' (and services in the case of RATP) positioning and communication and concomitantly their respective semic universe, their unique semio-narrative structure and their discursive structure in the form of manifest communications. Thus, his effort seems to be contained in a solipsistic universe, where the sole determinants of alternative brand futures are a brand's past and present communications, irrespective of competitive dynamics.

\subsection{Semprini's brand semiotics}

Semprini (1992) is perhaps the first author who attempted to furnish a comprehensive brand semiotic theory, by drawing in part on his predecessor Floch. They both assume as their point of departure Greimasian structuralist semiotics, the former rather implicitly and the latter explicitly. Semprini's purpose is to yield a theoretical base for unifying different aspects of branding, including positioning, segmentation, communication, but also to employ this theoretical base, rooted in semiotics, as a platform for long term brand management. The author christens this platform the «brand identity mix», comprising «the ensemble of elements that relate not only to the communications, but also to the wider marketing mix» (1992: 184), as well as to the discourse whereby this mix is manifested. 
For Semprini a brand is essentially an intersubjective contract between sender and receiver in perpetual motion (1992: 31-34). Brands constitute semiotic constellations in virtually infinite configurations. The signification of brands, however, is not exhausted in the relationship between sender and receiver, but depends on the concurrence of a constantly shifting competitive landscape, which is compounded by cultural transformations that impact on the value-systems of a brand's audiences. These factors contribute to what Semprini calls by allusion to the $2^{\text {nd }}$ law of thermodynamics the «entropy of the brand» (ibid: 37 ). Hence, «brand identity is the result of continuous interactions and incessant exchanges amongst three sub-systems that we call encyclopedia of production (sub-system A), environment (subsystem B), and encyclopedia of reception (sub-system C)» (ibid: 40).

Three conditions must be fulfilled for the maintenance of brand identity, viz. credibility, legitimacy and affectivity. The key requirement that must be fulfilled for the maintenance of credibility is brand coherence. Semprini conceives of coherence in a bifurcated manner, as linguistic coherence and as coherence in terms of systems of utilized representations.

Coherence is not a matter of truth / falsity in the sense of propositional logic, but of the internal coherence and the internal logic of a brand (Semprini 1992: 49). This position echoes Greimas's coherentist outlook of the text as logico-semantic simulacrum, even though not explicitly recognized as such by Semprini.

Legitimacy constitutes the continuity or diachrony requirement that must be met so that a brand may be recognized as credible. Lack of sufficient legitimacy in cases of positioning and repositioning, where a «brand seeks to appropriate a certain value or a certain type of discourse» (ibid: 129) is the primary driver behind brand failure. This attribute corresponds to what was termed earlier brand heritage, which concerns primarily the longevity of a brand in a given market and its relative standing in consumers' perceptions by virtue of its longevity.

The condition of affectivity concerns the emotional investment of a brand, which enhances the probability of brand selection and choice.

Semprini's structuralist semiotic heritage emerges quite forcefully in his account of how a brand identity system may be constructed. Evidently writing under the influence of Floch, but also drawing implicitly on basic Greimasian postulates, Semprini contends that a brand identity system is made up of a multiplicity of discourses, which mandates their hierarchical ordering. A brand discourse is made up not only of discrete elements, but also of differential relations among elements. In order to account for these relational structures among the elements making up a brand identity structure, Semprini proposes a three-level structural system that bears considerable resemblance to Greimas's system of signification as a multilevel generative trajectory. This system, exemplified in terms of Levi's brand signification structure, is portrayed in Figure 16: 


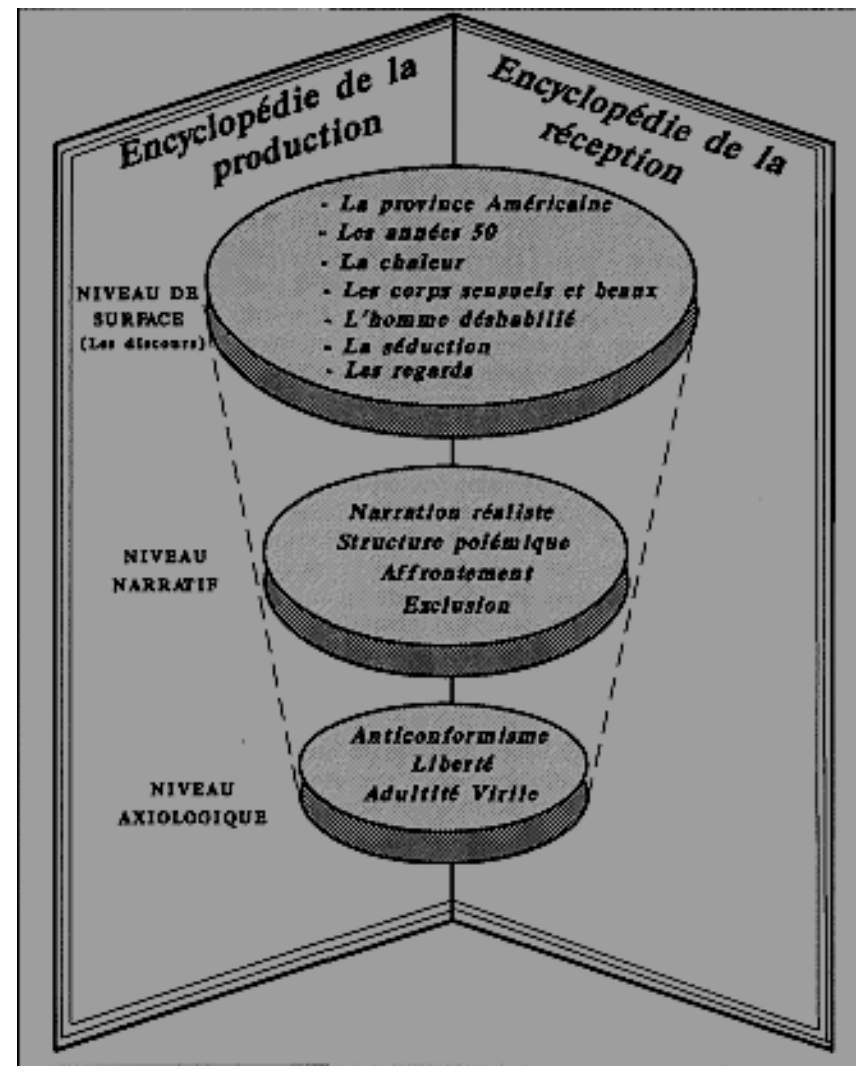

Figure 16: Semprini's brand identity system (1992: 59)

This perspective on brand identity distinguishes amongst three different levels of brand signification, in terms of depth/surface level signification, viz. the base or axiological level (also adopted by Hetzel: 2002), the narrative level and the surface/discursive level.

At the heart of a brand identity system lies the intermediate level of brand narrative. «At this level, the base values ${ }^{4}$ are organized in the form of narratives. A narrative grammar allows for the ordering of base values in relations of opposition» (ibid: 56). The narrative level allows for the endowment of abstract base values with concrete manifest representations, such as fleshing out the values of mastery and virility by situating the Marlboro brand myth in a rough and difficult environment. «The discursive or surface level is where base values and narrative structures are enriched by figures» (ibid: 54).. In other terms, the surface level is where a brand personality is invested with concrete features, such as face, bodily posture, profession, context of action and all the contexual elements that allow for a brand's identification and differentiation. For Semprini, following Levi-Strauss, there is no identity without difference, insofar as in order to confer identity to an object or concept it must be inserted in a system of objects and concepts (echoing Saussure). The figurative rendition at the surface level of a brand's narrative univocity and value identity fulfills exactly this requirement for identity through difference, which was identified in the previous section as one of the most tantalizing concerns in the maintenance of a brand identity structure and a

\footnotetext{
4 Note that in line with Floch, Semprini considers as base values those values in a consumer value system characterized by emotional and abstract associations, which in Keller's terms constitute secondary brand associations.
} 
master brand narrative. For example, in the case of Levi's brand identity «the actor (figurative level) who incarnates the hero (narrative level) who stands for anticonformism and individual liberty (axiological level) is hardly ever the same throughout the various advertising films» (idem). Even though the kernel of a brand's signification lies at the axiological level, the discursive level is responsible for fulfilling the condition of affectivity and furnishing what Semprini calls an «iconic» identity to the brand, thus confirming the mutually presupposing nature of depth and surface levels, as postulated by Greimas. Semprini implicitly recognizes that iconicity is a matter of contrived similarity or metonymic contiguity when he stresses that «the music of Dim or the logo of McDonald's are the keys for accessing the respective brand universes, which they evoke metonymically» (ibid: 57).

At this juncture, it is particularly important to stress that what is of particular value in Semprini's approach and by default Greimas's structural semiotics, which condition conceptually and methodologically this approach, is the ability to identify opportunities and threats for a brand's positioning and the possibility for maintenance of a brand identity not only at the manifest level, but as a system of interactions amongst three discrete, yet interlocking levels of analysis and synthesis. Thus, when pretesting an advertising film or a new brand identity system in terms of its appeal/credibility/differentiation among a prospective consumer pool, not only isn't it sufficient to gauge consumers' preference for certain stylistic elements regarding the manifest text of a brand narrative, but what is of primordial importance is how such elements relate to the underpinning narrative structure and brand image attributes as a brand's depth grammar.

What such a multilevel analysis points to is that the focal point of branding research and the prospect of maintaining brand identity is not simply a matter of components or elements, but of the modes of their multilevel inter-relatedness. Additionally, in comparison with the standard branding models in the marketing literature reviewed so far, this semiotic approach enhances the prospect of attaining coherence and consistency by integrating surface level stylistic elements in the brand identity system with brand image attributes, while attempting to justify the reason why they constitute integral elements. For example, assuming as our frame of reference Keller's brand knowledge structure (cf. Figure 7), what is lacking in the otherwise comprehensive picture of a brand identity system is the additional linkages to manifest ad textual elements. Given that the process of building and maintaining a brand identity system is a process of co-creation between sender and receiver, as portrayed in Kapferer's Brand Prism (cf Figure 4) and further explored by Elliott and Ritson (1995) and by Semprini from a semiotic perspective, omitting ad textual stimuli from a brand knowledge structure amounts to excluding the actual communicative interface whereby a brand identity is fleshed out. Regarding the mode of exposition of the interlocking levels in a brand identity system in the context of Semprini's account, what is still missing is an account of the modes of relatedness amongst the elements of the three levels, especially given that a simple laddering approach does not suffice in the face of highly figurative, tropical discourses. As an attestation of the indispensable role performed by surface level signs in building and maintaining brand image, Semprini cites the figure of the Marlboro man. Additionally, one 
may add anthropomorphic figures and cartoons, such as Kellogg's Tony the Tiger and the liquid cleaner Mr. Muscle.

Semprini complements his semiotic account of brand signification by operationalizing Floch's brand value system in discrete product categories and brands. Floch (2001) constructed a brand value system by extrapolating key value territories that emerged through a semiotic analysis of four years of Citroen's advertising communication materials. The fundamental building blocks he identified consist of the practical and utopian values, the former corresponding to functional aspects of a brand's ownership and usage (comparable to Keller's primary brand associations), whereas the latter corresponding to more abstract values (comparable to Keller's secondary brand associations). By projecting these fundamental values on a Greimasian semiotic square, Floch came up with their opposites in the form of critical and ludic values respectively, which were adopted by Semprini. This exercise furnished a universal brand mapping model, as portrayed in Figure 17:

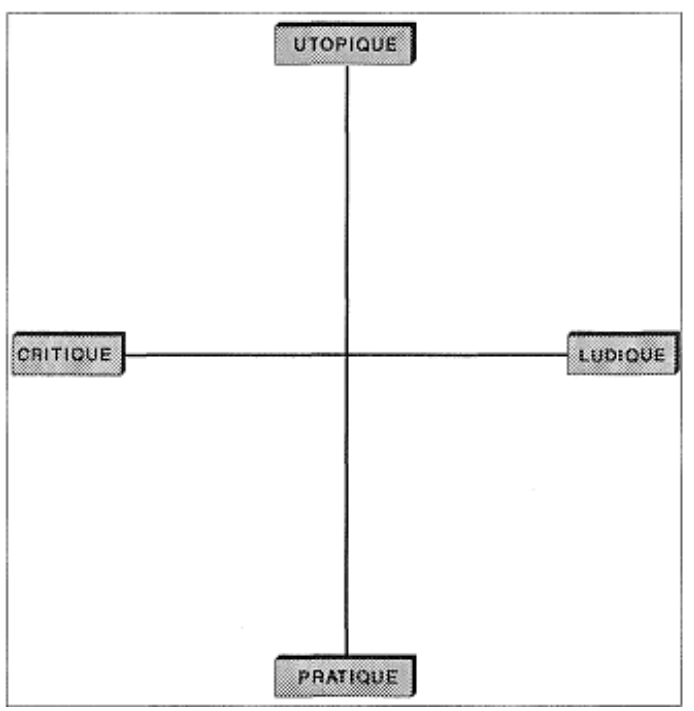

Figure 17: Brand values semiotic map (Semprini 1992: 79).

By virtue of their highly abstract nature, these four value dimensions may be interpreted in various ways, based on the product category and the sociocultural predicament at hand.

In greater detail, utopian values do not concern some sort of «higher humanity ideals», as stressed by Semprini, but a specific teleological framework underpinning the product category of concern. «If the practical valorisation has a tendency to be product-oriented, the utopian valorization is above all future-oriented» (ibid: 82). The utopian dimension is what foregrounds the evolution of a brand throughout its temporal manifestations. Critical valorization concerns the evaluation of the details of brands partaking of a product category by comparison to an external frame of reference and a hierarchy of values. Ludic valorization concerns the affective and emotional values attached to a brand. These generic value dimensions and concomitantly each value quadrant may be supplemented by more concrete ones, depending on the concerned category under scrutiny. The usefulness of such an abstract level of value mapping consists in its ability to accommodate brands from different categories, thus portraying a value framework from a more encompassing brandscape 
perspective. Additionally, the merit of such a value framework lies in pointing to alternative directions for brand repositioning, either due to maturity or to shifting consumer values and category drivers. However, «the limitation to a particular set of universal values constitutes a form of reductionism, of which the advantages in terms of comprehension and clarity do not attain to counterbalance the inconveniences linked with psychodemographic variations» (Pasquier 2005: 25).

\subsection{Danesi's brand semiotics}

Even though Danesi is not approaching branding explicitly from within a structuralist framework, a considerable portion of his metatheoretical apparatus bears considerable resemblance to structuralist approaches, as will be argued in due course.

A particularly appealing facet of Danesi's approach to branding consists in his emphasis on the peculiar logic underpinning branding discourse, which he describes as poetic logic. «The term 'brand logic' is being used more often in place of 'brand image' in the relevant literature to provide a conceptual framework to explain the 'logic of branding'. But, in my view, the more appropriate term is 'poetic logic' [...] the logical reasoning involved is hardly deductive or rational, it is rather based on a poetic sense of the meaning nuances built into words» (Danesi 2006: 114)

The exemplary manifestation of this poetic logic that inheres in brands' signifying kernels is the metaphorical dimension of branding language. «Brands are essentially metaphors [...] As such, they become themselves constructs for further rhetorical processes» (ibid: 115). By virtue of their inherently metaphorical dimension brands are expressed through advertising as «workings of the unconscious» (ibid: 74), thus confirming a tentative parallel between what I call the «brandwork» and Freud's «dreamwork» ${ }^{5}$. The cogency of this parallel is further augmented by Danesi's elaborating the ad text in terms of connotative chains (Danesi and Beasley 2002: 103-107) or the associative syntagmatic relationship among signifiers in a given text. In order to understand Danesi's approach to brand signification and further illustrate its derivation from structuralist semiotics, let us proceed with an overview of its key conceptual components.

Danesi's striking resemblance to Greimas's generative trajectory of signification is evinced while drawing a distinction between surface and underlying textual levels, which may be conceived as a novel rendition of Greimas's distinction between surface and depth structures, accompanied by respective grammars. The underlying level is defined as «the hidden level of meaning of an ad text, also called the sub-text» (Danesi and Beasley 2002: 42). The surface level is «the physically perceivable part of an ad text» (idem). The authors also identify surface textuality with the conscious, denotative dimension and the subtextual layer with an unconscious, connotative dimension (ibid:129). This distinction harbors a potential

\footnotetext{
${ }^{5}$ For further qualification of the parallel between «brandwork» and «dreamwork» see my paper «Repressenting the manimal: A semiotic/psychoanalytic approach to the strategic importance of anthropomorphism in branding» (available at http://papers.ssrn.com/sol3/papers.cfm?abstract id=1999716 )
} 
misunderstanding insofar as «overt» textuality as advertising language or manifest brand discourse, as against the sub-text, is highly figurative. By virtue of its figurative status, it is open to the connotative dimension, hence the distinction may become blurred. In fact, it may be claimed that if such a relationship held, it would be the other way round, viz. the subtext as a brand's intended positioning constituting the denotative dimension, which is manifested on the surface through a connotative chain, which reflects the previously drawn distinction between the logical organization of a brand's positioning statement as against its figurative ad textual manifestations.

In his later work Brands Danesi seems to depart from his earlier conception of textuality. As against the position adopted in Persuasive Signs, where the manifest text and subtext are aspects of an overarching textuality, in Brands he defines textuality as «the form they [my note: ie. brands as significations systems, based on the terminology employed by the author] are given in advertising campaigns can be called their 'textuality'» (Danesi 2006: 70), thus equating textuality with the manifest level. The manifest level of a brand's discourse was also identified in Persuasive Signs with the concept of narrative. Yet, subtext is retained as a brand's signifying kernel, albeit in some sort dislocated from textuality as an allencompassing process, involving both the manifest text and the sub-text. «And although the details of the ads will change, in line with changing social trends, the subtext tends to remain the same, since it is the level at which the signification of a brand is embedded» (ibid: 74). Again, it may be claimed that these concepts constitute a simplified version of Greimas's levels of the trajectory of signification. The risk involved in reducing the levels of the trajectory consists in missing out on important aspects of a brand's surface and depth grammar, the transitions among strata and the operations of semantic transformation involved during transitions.

The aforementioned connotative dimension is complemented by the concept of connotative chains. Connotative chains «constitute the underlying level of the ad's textuality [...] There are various kinds of connotative chains that characterize subtexts. The most common is the one that is forged from narrative sources; i.e. it constitutes a chain of meanings linked together by themes, plot-lines, characters and settings suggested from the implicit storylines built into the surface presentations» (Danesi and Beasley 2002: 104). Danesi's connotative chains also resonate the chains of homologation in Greimas's terms, which are responsible for linking analogically elements across the strata of the generative trajectory, as will be displayed in due course. In fact, connotative chains constitute a simplified version of Greimas's homologation chains.

From a brand planning point of view, what appears to be lacking in the process of coining connotative chains is an explicit linking of these chains with the motivation of the advertiser, which consists in a logically structured positioning statement and at the same time the plane of denotation, compared to which, one may make sense of the tropical configurations uncovered through connotative chains. Without taking into account a brand's positioning statement as semiotic constraint in the formation of connotative chains, the latter are likely to surface in all sorts of dissonant ways. This threat of dissonance vis a vis a brand's intended positioning (also called aberrant positioning or aberrant decoding) poses a considerable 
challenge to the postulate that «the higher the number of connotations a brand generates, the greater its psychological force» (Danesi 2006: 37), a standpoint that is also shared by Keller, who postulates that richness of brand associations is a key determinant of equity strength.

The ability of an advertising text's signification to avoid yielding to unlimited semiosis is attributed by Danesi to a set of constraints, such as «conventional agreement as to what a sign means in specific contexts, the type of code to which it belongs, the nature of its referents» (ibid: 43), a pragmatic approach to signification that is also prevalent in Eco (1976) and, with social phenomenological overtones, in, Sonesson's account of Husserl's Lifeworld . At this stage it suffices to note that the assumption of conventional agreement between sender and receiver and the codedness of the sign is not enough in accounting for the poetic deviance of the advertising text, which occasionally challenges tropically this conventional agreement, rather than ratifying it, as Mick \& McQuarrie have repeatedly shown. The need for semiotic constraints is inextricably linked to the ambiguity of a text, or the ability «to generate various kinds of subtexts from the same layout» (Danesi 2006: 101). The interpretive risk inherent in decoding, as. «the process of uncovering a subtextual meaning in an ad text», is also present in the process of structuration (as will be argued in section 5) during encoding, insofar as the more tenuous the constraints the higher the ambiguity,. The difference between decoding and structuration concerns a shift in focus from extra-semiotic codes to the strata in a brand's trajectory of signification that must be crossed in order to bring about this «uncovering», as well as the modes of relatedness among the elements of different strata, which is not accounted for by the process of decoding. Decoding and structuration are complementary processes, which implies that in order to enable decoding we must first give an account of brand text's structuration, as will be endeavored in section 5 .

The typology of levels of signification on offer, as already stressed, constitutes a reframing of semiotic structuralism, as previously pursued by Floch and Semprini.

\subsection{Other structuralist approaches to brand image creation}

Cossette (1973) offered a simple approach to the planning process of what he formulated as advertising or functional image, which essentially consists in a basic structuralist perspective, inspired by Saussure;s structural linguistics, of how brand image is created through advertising communication.

By drawing on the fundamental Saussurean premise of the sign as a relationship between signifier and signified, the planes of denotation and connotation and the syntagmatic/paradigmatic axes of combination and selection of signs respectively, he carves a semiotic model that is characterized by accessibility and comprehensibility to practitioners.

As an extension of the traditional commutation test, he seeks to establish rules whereby signifying units are chained [the process of enchaînement].

In contrast to the approach pursued in this endeavor (see section 9) he locates denotation in a natural language, in which «the signified is strictly tied up with the referent» (Cossette 1973: 
97). He localizes connotation in mythical and symbolic signifieds, which he deems concern the realm of rhetoric. The proposed model is enriched by recourse to Durand's earlier classification of rhetorical schemes and tropes, such as metaphor, metonymy, allegory, hyperbole into five rhetorical operations that correspond to the syntagmatic axis (repetition, adjunction, substitution, suppression, exchange) and five types of relationship that correspond to the paradigmatic axis (identical, similar, opposed, different, falsely homologous), which yields the grammatical backdrop of what Cossette calls «functional image», that is image, which is geared towards persuasion.

By blending semiotics with rhetoric he suggests a nine-step process of advertising image planning, as illustrated in Figure 18.

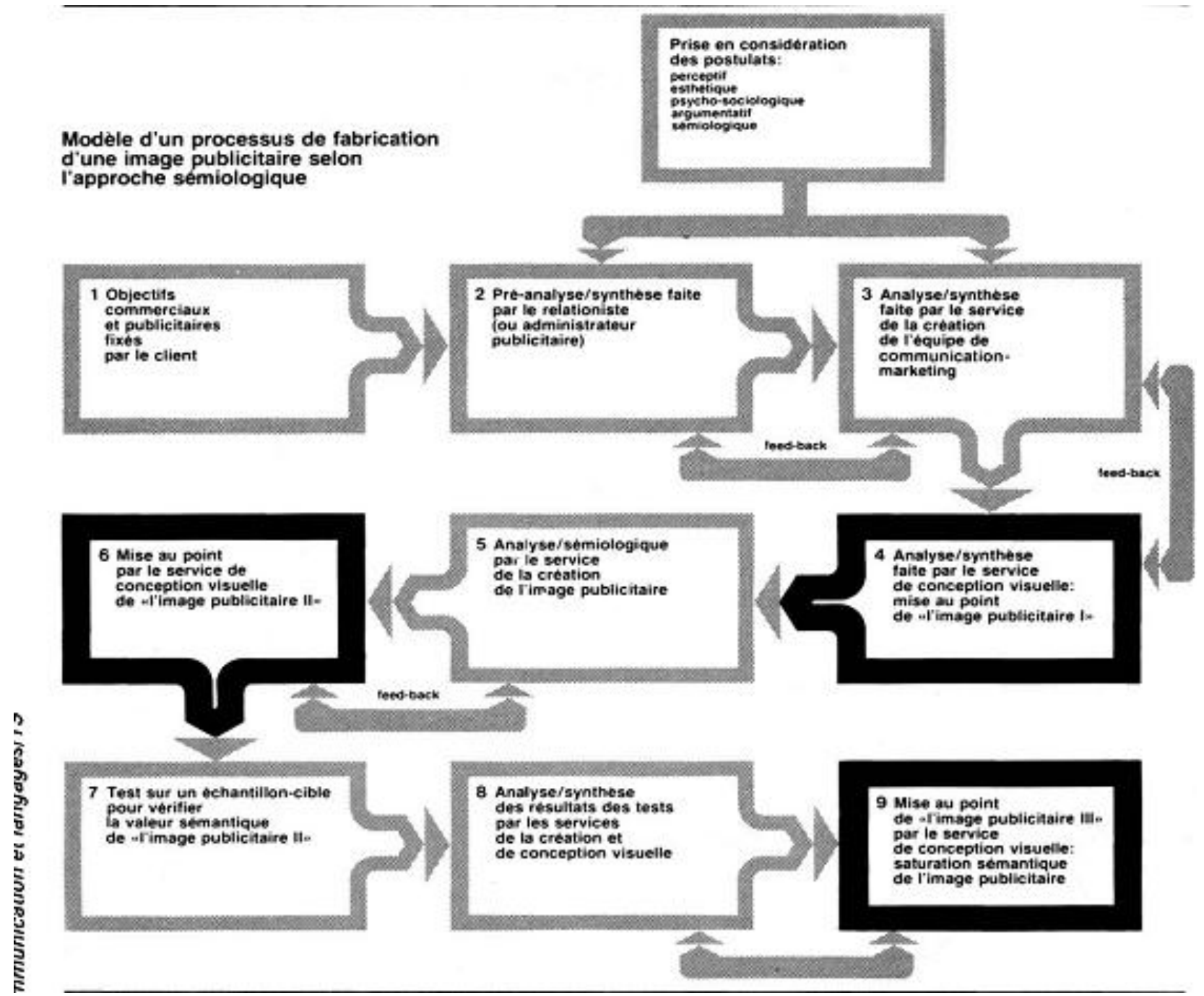

Figure 18: Cossette's model of the creation of advertising image

The process aims at streamlining perceptions of the employed signs in advertising communication among all stakeholders involved in a brand image creation process (at least during the encoding stage), viz. the client service/account planning team of the advertising agency, the brand management team and the market research team. Streamlining of perceptions among the involved stakeholders is effected by assuming as a common ground for 
the appropriateness of the employed stimuli (mainly visual signs or iconemes, as defined by Cossette) a grid containing salient criteria, such as harmony, equilibrium, grain, orientation, angle. The proposed iconemes are evaluated in terms of their degree of pertinence against the intended signifieds or functional images.

Hetzel adopted Floch's adaptation of Greimas's trajectory of signification in branding by assuming the three strata of the trajectory as the key pillars of his brand semiotic approach. In his book Planet Conso (2002) he divides the three strata of signification of a brand identity system into the axiological or depth level, which comprises the key source of identity or the values that bestow continuity on a brand, the narrative level, which allows for the staging of a brand's values and the discursive or surface level, which enriches the narrative with figures.

Pasquier (2005) attempted to account for the focal areas of research in various semiotic approaches alongside the strata of the generative trajectory, as follows:

\begin{tabular}{|l|l|l|}
\hline Level of analysis & Content & Concepts and models \\
\hline Study of significations & $\begin{array}{l}\text { Research of signs- carriers } \\
\text { of signification }\end{array}$ & $\begin{array}{l}\text { Signifiers, } \\
\text { denotation, connotation, } \\
\text { proof of commutation }\end{array}$ \\
\hline $\begin{array}{l}\text { Study of narrative } \\
\text { structures }\end{array}$ & $\begin{array}{l}\text { Analysis of different } \\
\text { functions of discourse and } \\
\text { the roles of actors } \\
\text { (different phases of } \\
\text { communication) }\end{array}$ & Narrative schema \\
\hline $\begin{array}{l}\text { Study of depth structures } \\
\text { of signification }\end{array}$ & $\begin{array}{l}\text { Research of elementary } \\
\text { structures of signification } \\
\text { of an entire discourse } \\
\text { (research of differences } \\
\text { that give rise to } \\
\text { signification) }\end{array}$ & \\
\hline
\end{tabular}

Table 1: Research streams alongside the various levels of the trajectory of signification (Pasquier 2005; my translation)

As Pasquier notes, the first level (study of significations) concerns the identification of the signifying function of signs in communication. The signifying units may be limited to a single sign (a word or an object in a message), but may also correspond to a group of signs (a phrase or an ensemble of objects).

The second level (study of narrative structures) corresponds to the form of discourse. Any textual form may be organized according to the narrative schema. By virtue of being inserted into a narrative structure, the narrative schema must accomplish the task of segmenting every narrative into discrete phases, independently of their chronological ordering. What is of primary importance is the logic of discourse.

The third level of analysis concerns the depth signification of messages. 
Pasquier correctly points out that the majority of branding related semiotic studies concern advertising communications, not strictly connected with a holistic approach to brand signification, as put forward by the aforementioned key authors in brand semiotics. By focusing partially on single aspects of the trajectory of signification, semiotic studies may become oblivious to the fundamental principle that brand communication is the manifestation of a brand's depth grammar, its brand identity structure and its image edifice, which precede and ground brand communications. As Mick et al (2004: 16) stress in their seminal global overview of semiotic approaches to various marketing related research areas "semiotic researchers have conceptualized branding as a multifaceted contract between the manufacturer and the consumer, focusing especially on communication and meaning in packaging, names/logos/trademarks, and advertising" , but not necessarily with how these various sources of signification are chained across the different strata of the trajectory of brand signification.

Approaches to brand image creation have also been coined by practitioners in the field of marketing semiotics. Let us briefly describe some of these approaches, based on their direct relevance to brand image research (and not research focusing simply on decoding advertisements or encoding packaging stimuli) in order to demonstrate how key concepts from key structuralist thinkers, such as Eco, Jakobson, Levi-Strauss, Barthes and Saussure have been put to practice, even in a piece-meal and selective, yet indubitably insightful fashion..

Valentine (2001) of Semiotic Solutions draws on Jakobson's focus on metaphor and metonymy in order to yield a heuristic mechanism for encapsulating emergent codes on which a brand myth may be predicated, which she calls «Imaginative Metonymy» .

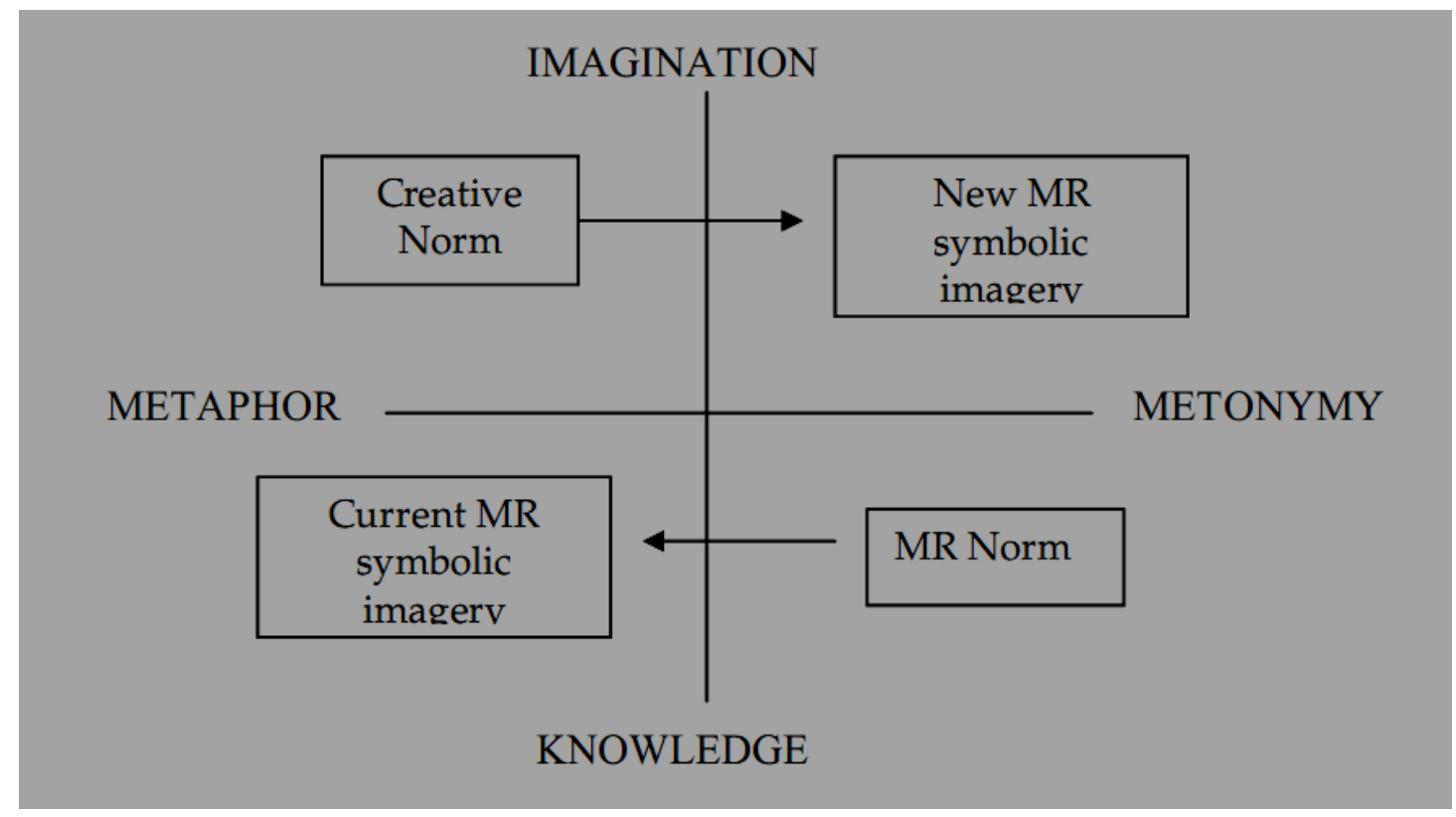

Figure 19: The imaginative metonymy map (Valentine 2001: 24) 
«Currently MR is stuck in the bottom half of the quadrant, working to the codes of knowledge; either expressed metonymically, or through tired and cliche'd symbols and metaphors. If however, we shift to the codes of imagination, which also encompass change, ambiguity, liminality, feelings and hanging loose, we have a new symbolic register, Imaginative Metonymy» (idem).

Evans (1999) illustrates how the structuralist notion of «Code», popularized by Eco in his Theory of Semiotics (1976) may be operationalized in applied marketing research with view to segmenting cultural codes into residual, dominant and emergent.

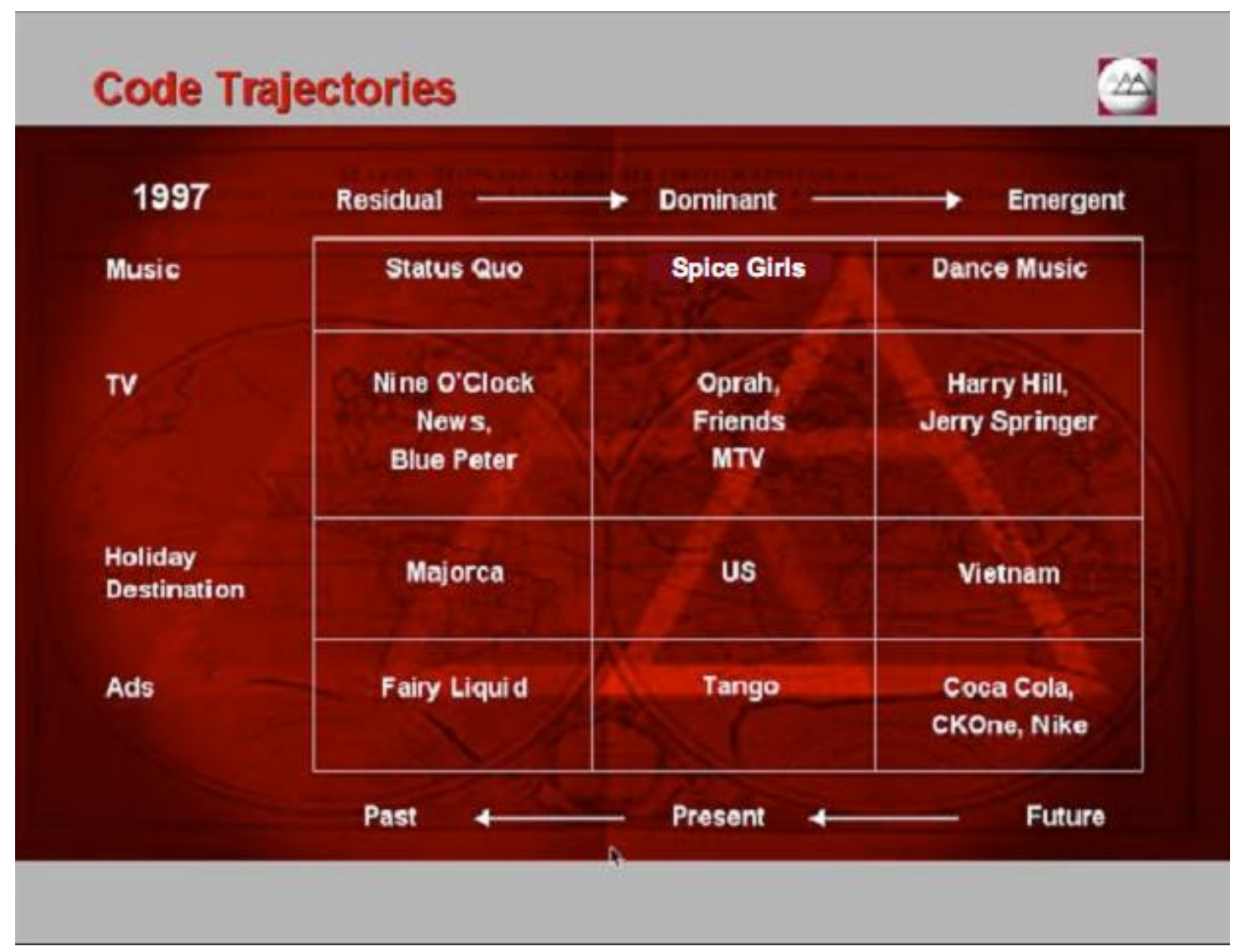

Figure 20: Code trajectories (Evans 1999)

Another interesting model that sprung up in an attempt to create a global semiotics based brand planning process that links cultural codes (defined as «cultural software»; Evans and Harvey 2001: 176-177) with brand image attributes and advertising stimuli in a competitive setting was furnished by the Added Value agency for Guinness beer. The agency analysed verbal, visual and audio stimuli of TV and print ads and dominant, emergent, residual codes in six representative markets, thus yielding a verbal and visual snapshot of global beer meanings. 


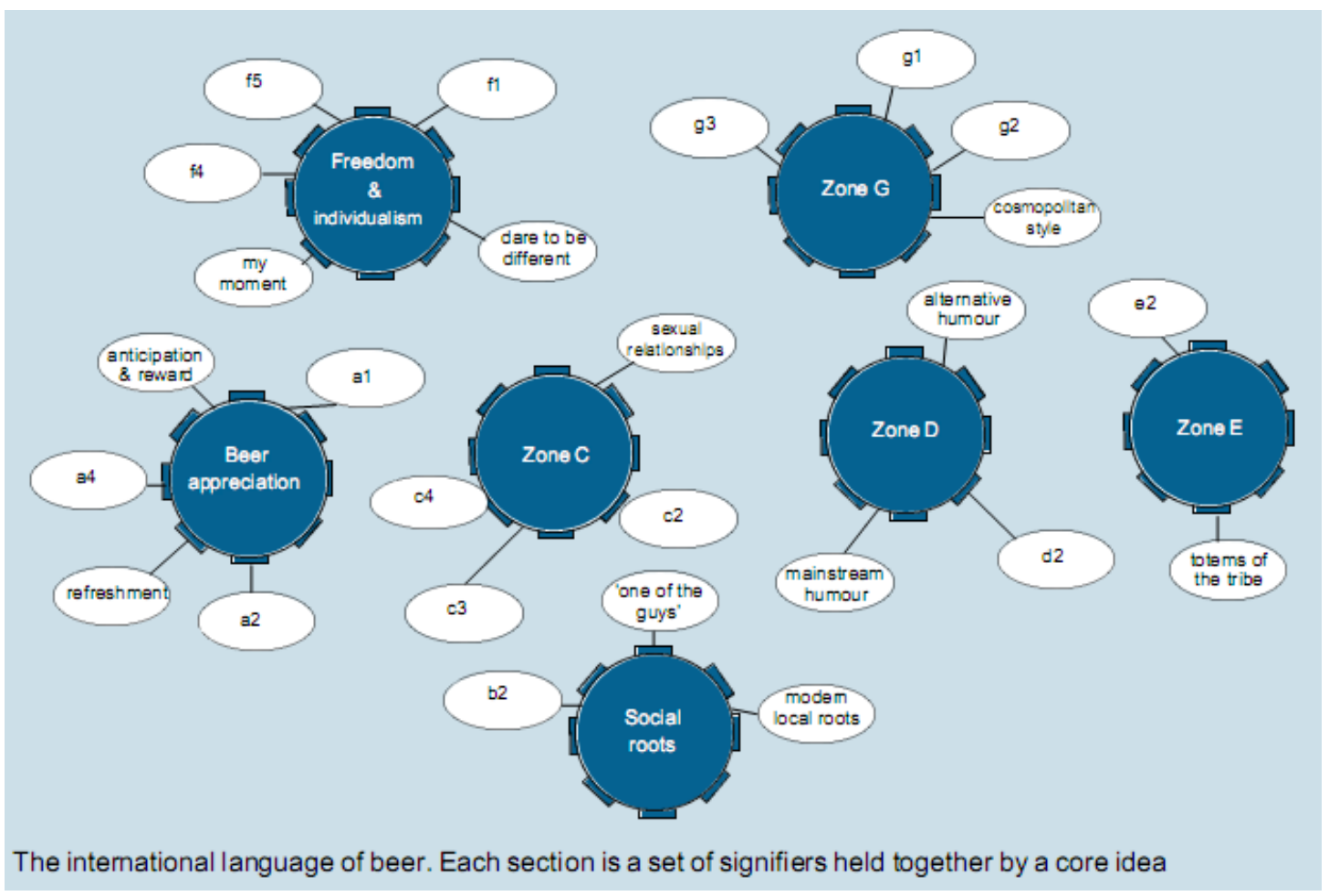

Figure 21: International beer codes (Harvey and Evans 1998)

The ensuing mapping exercises resulted in twenty-six codes, which were narrowed down to seven clusters. The project culminated with the creation of a competitor advertising decoding toolkit, which was adopted as an advertising planning platform by Guinness's brand management teams across the globe.

Alexander (1996) drew on Levi-Strauss's structuralist anthropology in order to deconstruct the mythic nature of brands. According to Strauss the basic function of a myth is to resolve oppositions. By analogy, brand personae, such as the Persil mum, afford to relieve cultural tensions, by reuniting them in a brand structure, such as «the 'distance' and detachment of a factory-produced, high-tech washing agent on the one hand, and the 'closeness' of a caring, loving member of the family on the other. From this contradiction, we could define the Persil myth by an expression such as caring detachment» (Alexander 1996). Alexander contends that the stronger the oppositions, the stronger the myth and hence the more impactful the resulting brand positioning.

Analysis of codes is a standard enterprise in applied brand semiotics. Complementary to the above furnished examples of the analysis of advertising, brand personality and cultural codes from brand semiotics practitioners, design codes analysis of a packaging structure is normally undertaken with view to positioning differentially a brand on shelf. Cavassilas (2009) of Semiopolis offers the example of Smoothies' adopting an infantile design code in order both to differentiate itself from Bio products, and emit its key positioning statement involving a wholly fresh, without any preservatives brand proposition. 


\section{What is the relevance of the generative trajectory of signification for the organization of a brand's image structure?}

In terms of a marketing approach to branding, a brand personality consists in core and peripheral image attributes. Occasionally, brand personality is portrayed in the form of concentric circles, where core image attributes populate the center of the concentric circular system and peripheral image attributes the outward layers of the system. However, such approaches are not informed by a metalanguage, such as the one offered by structuralist semiotics, but constitute metaphorical portrayals rooted in common parlance.

The value of informing the brand creation process by drawing on a semiotic paradigm rests with furnishing such a metalanguage.

Thus, in structuralist semiotic terms, a brand's semantic kernel as core brand identity consists in a semic micro-universe. The key brand image attributes or semes that make up its semantic edifice constitute nuclear semes, which, while enriched with contextual semes or classemes in discrete communicative contexts, make up sememes as a brand's core and peripheral semantic territory respectively. Nuclear semes constitute the minimal units of signification of a brand langue or its core image attributes. What was originally conceived by Greimas in Structural Semantics as a semic micro-universe and particularly a semic category was redefined by Rastier in Interpretive Semantics as semic molecules, which combine at least two semes. The semic micro-universe makes up a brand's depth grammar, which becomes manifested through the elements and the particular syntax of a surface grammar in the form of two additional strata in the generative trajectory of signification [parcours génératif ${ }^{6}$ ], viz. semio-narrative and discursive structures (cf. Greimas and Courtés 1979, 160).

Semio-narrative structures contain the depth meaning of a discursive structure and «furnish the form of its organization». In terms of brand structure, semio-narrative structures constitute what has already been termed as brand master narrative. However, a brand master narrative should not be viewed solely as a canonical narrative schema. This is a crucial difference between literary discourse and brand discourse. A brand master narrative includes a brand's key positioning statement, featuring its nuclear semic brand image structure. They are distinguished from discursive structures as the latter are situated at a more superficial level in the generative trajectory. Discursive structures allow for manifestation at the discursive level of semio-narrative structures in the face of an enunciative predicament (Greimas and Courtés 1979, 364-365). Discursive structures correspond to the manifest texts of a brand master narrative, such as advertising (TV, print, radio, outdoor, ambient), but also experiential events (i.e. roadshows, in-store sampling/competitions), sponsorship and any form of brand communications, Further to the above let us portray the model of a brand's generative trajectory of signification, by interpolating the discrete brand semiotic strata on Greimas's parcours génératif:

\footnotetext{
6 Let it be noted that Rastier (1989) redefined the three levels of the parcours into micro, meso and macrosemantic levels.
} 


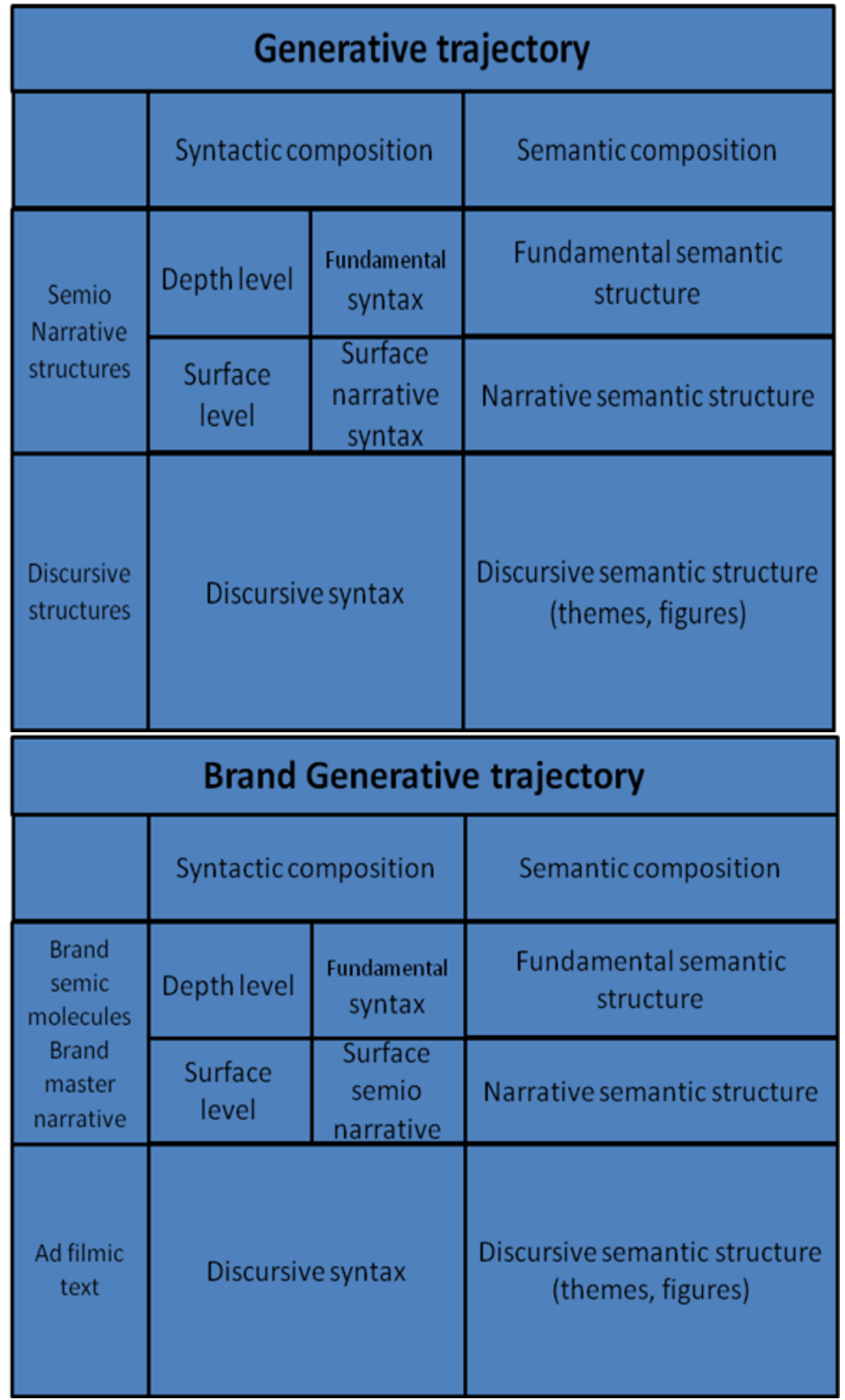

Figure 22: A brand's generative trajectory of signification

\section{The key structuralist operations involved in the maintenance of a brand's depth grammar}

The above model represents a topline view of how a brand's various semiotic strata of signification hold together. In order to yield a methodological brand image creation research framework from a structuralist semiotic point of view, which links all three strata of the generative trajectory of signification, we must display the key structuralist operations involved in bringing about brand signification. These operations consist in structuration, homologation, isotopy, reduction, redundancy and recurrence. Prior to analysing the role of each operation in greater detail let us describe how they interact and at which level(s) of a 
brand's generative trajectory with view to maintaining a brand's image kernel, starting from the surface and moving progressively to depth grammar:

Structuration transpierces all levels and confers continuity in signification by subsuming all strata under a coherent structural backbone. Structuration is effected by establishing homologies among elements of the various strata, while homological relations allow for the discernment of isotopies. Isotopies are established through the operation of recurrence of common themes. Recurrence is incumbent on the operations of reduction and redundancy.

The process of structuration may be portrayed schematically as follows

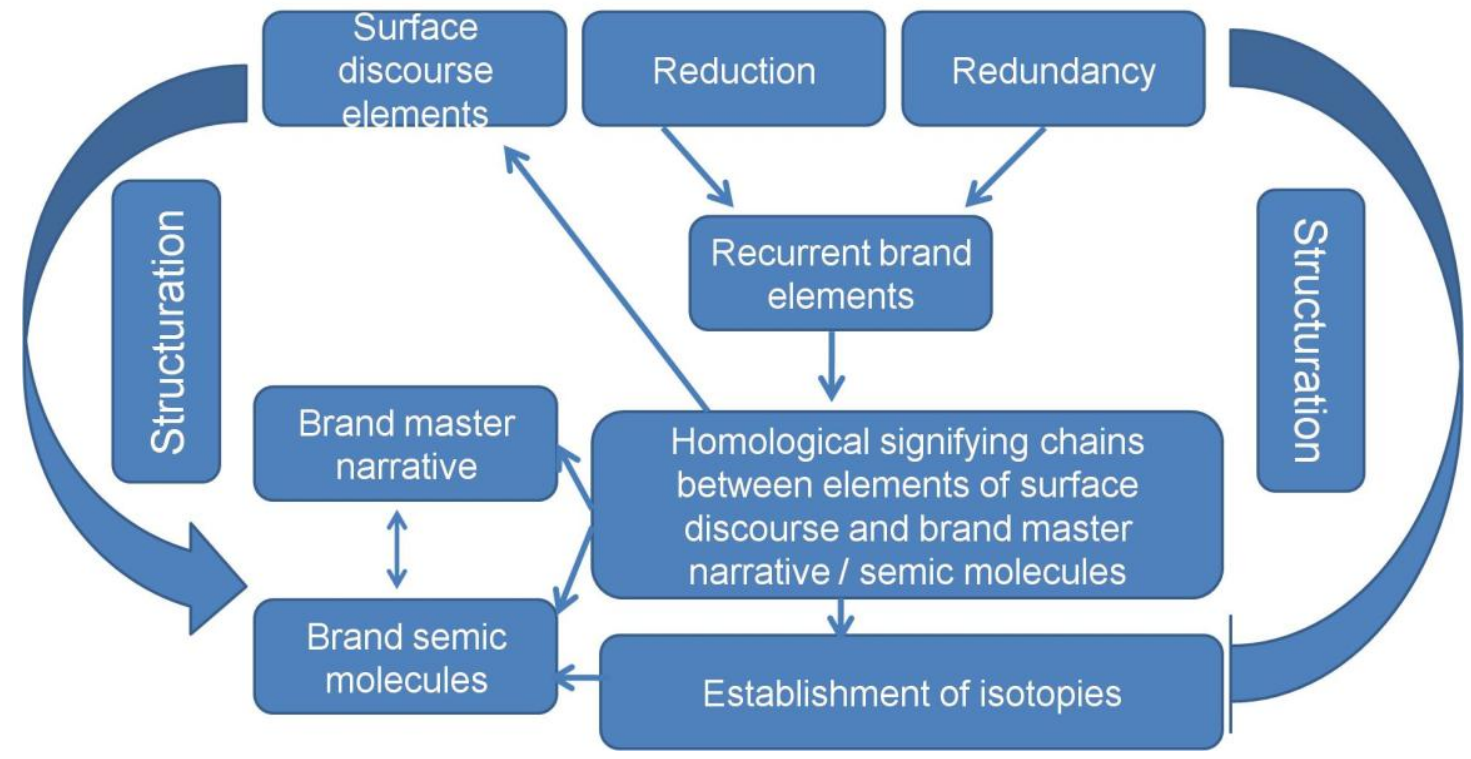

Figure 23: The process of structuration

In greater detail:

Structuration «is one of the procedures of semantic analysis [my note: semantic analysis corresponds to Greimas's system of structural semantics], responsible for carrying out, on the one hand, the reduction of parasynonymic sememic occurrences into classes and, on the other hand, the recognition of the homologation of semic categories (or sememic oppositions)» (Greimas and Courtés 1979, 360). Structuration's dual role, thus, transpierces the entire generative trajectory insofar as it is concerned both with the establishment of homologies between semic categories at a deep level and the classification of recurrent sememes at a surface level (as underpinnings of recurrent parasynonymic lexemes- even though, as Rastier notes, sememic recurrence is not exhausted in parasynonymic relations). In fact, if there is a way of organizing the semic micro-universe of a brand's discourse as master narrative in the context of an ad filmic text, then structuration entails starting from the classification of recurrent elements of the surface discursive structure (both on an intra-filmic, as well as interfilmic level, ie recurrences throughout variable same brand executions), reducing them to sememes through a (provisional) rationale of contrariety (where the contrary poles of the ensuing pairs will also encompass sememes that emerge from competitive brand discourses), 
further decomposing sememes into classemes and nuclear semes and ultimately showing which semes constitute a brand's signifying kernel. This is the classificatory part of the process of structuration and is concerned with effecting redundancy to peripheral cues on the surface of an ad filmic text, which results in the required reduction whereby sememes and semes may be recognized as such.

Homologation is an operation of semantic analysis that is applicable to all levels of the trajectory. It may be considered as a rigorous formulation of analogical reasoning. In its simplest form it concerns a relationship of the type $A: B:: A^{\prime}: B^{\prime}$, where term $A$ stands in an analogical relationship with term A' by virtue of their mode of relationship with terms $B$ and B' (Greimas and Courtés 1979).

The operation of homologation entails the construction of homological relationships not only on each specific stratum of the generative trajectory, but also on an inter-strata level, for example by pairing sememes with lexemes or units pertaining to other modes of figurative ${ }^{7}$ discourse (i.e. shots, sequences, but also individual audiovisual elements). It is through the ultimate formation of a complex chain of homologation that brand signification may be mapped out and issues of brand coherence and communicative consistency may be tackled not only at the level of an individual ad filmic text, but, even more importantly from an iterative brand planning perspective, throughout variable ad executions (and certainly this process of structuration may extend and encompass other vehicles in an Integrated Marketing Communications plan).

Isotopy is a multifariously used concept in structural semiotics. At the heart of the concept lies the notion of recurrence, which may concern either the plane of expression or content or both. Eco (1976) expands the notion in order to encompass even purely stylistic isotopies, while in Semiotics and the philosophy of language (1986) he furnishes an expanded list of isotopies. Its main use consists in discerning correspondences among the various strata of the generative trajectory. In terms of correspondences between the figurative and the thematic or the discursive and the narrative levels, various combinations of correspondences are possible, such as between two or more figurative elements and a single narrative element or between different complexes of figurative elements and different themes within the same text, as will be illustrated in this paper by reference to the ad filmic texts of Johnnie Walker (cf.sections 7 and 8). Isotopies furnish a reading grid that allows for a homogeneous reading of a text (Greimas and Courtés 1979:197-198).

Recurrence is the «iteration of ocurrences in the interior of a syntagmatic process, which manifests, from the point of view of signification, regularities that serve the purpose of the organisation of an enunciated discourse. The recurrence of a certain number of semic categories, for example, institutes an isotopy» (Greimas and Courtés 1979: 308).

\footnotetext{
7 Notice that the term «figurative» has been employed in two senses throughout Greimas's writings. In the initial sense employed in Structural Semantics (1966) it refers to the nature of the elements that make up the discursive level, whereas in Figurative Semiotics and the Semiotics of the Plastic Arts (1989d) it refers to modalities other than verbal discourse, mainly of the visual register, but not addressing the moving image.
} 
Reduction is «one of the operations of semantic analysis that is integral to structuration. It consists in the transformation of an inventory of sememic occurrences of parasynonymic ${ }^{8}$ nature, into a constructed class, which is invested with an arbitrary denomination (or semimotivated) at the level of a descriptive language» (Greimas and Courtés 1979, 309).

Redundancy is a term that first appeared in the context of information theory. «It designates for a given quantity of information the distance between the minimal number of signals (or operations of encoding and decoding) required for its transmission and the number of signals actually utilized» (Greimas and Courtés 1979, 308-309). Redundancy is geared towards the maintenance of sememic regularities.

These key operations that have been singled out from Greimas's massive structuralist semiotic system are primarily responsible for maintaining a brand identity structure and a semic nucleus, consisting of core brand image attributes. In the ensuing sections I will demonstrate how the application of these operations allows for the construction of a signifying chain that cuts across the strata of the semiotic trajectory with view to uniting elements of a brand's manifest discourse with its master narrative and its semic brand image nucleus.

\section{The master brand narrative in focus and the role of the énoncé in brand communications}

Semio-narrative structures are situated in between a brand's depth grammar and the surface discursive level of the ad text. Insofar as brand signification emerges in the process of communication, the function and the mode of the organization of the ad signifiers at the semio-narrative level is crucial for the maintenance of a master brand narrative. However, Greimas's generative trajectory should not be conflated with narratological models ${ }^{9}$. The semio-narrative level is an integral stratum in a brand's signification process, and not capable of accounting per se of how brand signification morphs along the trajectory. Approaches that seek to reduce a brand's signification to "story-telling" constitute over-simplified forms of the potential embedded in Greimas's multi-level parcours generatif.

In this section Greimas's narrative grammar will be displayed in order to illustrate how ad signifiers function in the maintenance of a brand's master narrative.

Narrative is defined by Greimas (1971) as a sequence of narrative énoncés, where énoncés are equivalent to units of discourse or signifiers at the plane of the form of expression. «Two conditions, however, must first be fulfilled: a) the narrative énoncés must possess a

\footnotetext{
8 Greimas employs parasynonymy, ie quasi-synonymy, in two respects, first with regard to surface structure lexemes (and the same would apply to any elementary unit irrespective of modality, ie coloreme, cineme, videme, vesteme etc) and second with regard to depth grammar sememes. Insofar as the plane of immanence that regulates the function of sememes requires the manifest discursive level of lexemes for the constitution of a synonymic relationship between sememes, the comparison of lexemes with view to establishing a relationship of parasynonymy rests with their parallel reading from a sememic point of view.

${ }^{9}$ For a strictly speaking brand narratological model see Dahlen et al 2010 :
} 
determined and foreseeable canonic form, and b) the relations between énoncés which constitutes them in sequences of énoncés must be made explicit» (Greimas 1971, 798). The canonical form of the énoncé implies the presence of invariants, which Greimas traces in the syntactic function of the verb (while drawing on Tesniere's syntax) as the nucleus of the énoncé. The subject and object related by the verb are called actants. Let us recall by drawing on the figure of the generative trajectory that actants are elements of the semio-narrative syntax and not of the manifest discursive syntax, and by implication they should not be confused with the actors involved, for example, in an ad filmic text. Actants may be anything from humans, non-human objects, concepts and in our case brands.

For example, the main actor in Johnnie Walker's ad film is the android (see section 7), whereas the actantial subject at the semio-narrative level is the brand itself. Greimas further postulates that «the narrative énoncé and narrative as a whole allows for the interpretation of the narrative model at the epistemological level, as one of the fundamental forms of the organization of the imaginary» (ibid. 799). Thus, a master brand narrative concerns the recurrence of a particular network of relationships among actants as a semio-narrative syntactical and semantic reconstruction of units of discourse or elements and sequences of énoncés. At this juncture Greimas distinguishes between narrative and non-narrative énoncés. Let us sharpen this distinction based on the semio-narrative and discursive levels of the brand's trajectory as the manifest énoncé or unit of discourse, as already described and the latent énoncé or the énoncé at the semio-narrative level or the énoncé behind the énoncé pertaining to the brand's master narrative. In terms of communication, the latter, according to Greimas may be an object or a message (or both).

Without going into further details about the notation involved in the semio-narrative syntax, let us conclude this section with reference to the way wherebv the actantial structure shapes the messages or énoncés of manifest communication by imposing a logical order on the surface imaginary text (or ad filmic text). In fact, this intermediate level of semio-narrative structures (of which a more expansive outlook is furnished in Du Sens I) matches in marketing practice the intermediate level of the production of branding discourse as the advertising concept, occasionally coupled with the film's storyboard which explains how the elements of the advertising concept are inscribed in distinctive shots and sequences of the ad filmic text (also coupled with notes about production techniques involved in bringing about the intended signification, such as close-up, fade in/out, reverse shot etc.). The advertising concept is the intermediary stage between a brand's positioning statement that portrays its semic microuniverse and its manifest ad filmic discourse, in the same fashion as a brand's master narrative mediates between its depth image grammar and its textual manifestations. Brand coherence and the maintenance of a brand's core identity concern primarily the successful encoding, recurrence and recognition of such nuclear and contextual image attributes in a brand's master narrative. 


\section{Commentary on the binarist organization of a brand's depth grammar and the perils of approaching it in a non brand categorical framework}

Semes are relational attributes. Hebert (2011) identified a variety of possible structural relations, alongside different criteria. For example, a relation may be reflexive if it links a term to itself or transitive if it links a term to one or more terms. Simultaneity (or concomitance) is the relation between terms associated with the same initial and final temporal positions and succession is the relation between terms in which the final temporal position of one term precedes the initial position of the other term. A presential relation is a relation in which the presence or absence of one term indicates the presence or absence of another term. Identity is the relation between terms that have all identical characteristics. Alterity is the relation between terms that possess no identical characteristics. Relations of inclusion comprise mereological, set and typological modes. Mereological or holistic inclusion involves wholes (such as a word) and parts (such as the letters in the word). Set inclusion involves classes (such as the class of words) and elements (such as a particular word). Typological inclusion involves types (models, such as the sonnet genre) and tokens (more or less complete manifestations of a model or type, such as a particular sonnet that is more or less regular). However, in terms of relations of homologation Hebert confines them in analogical oppositional pairs, even though the analogical status of the corresponding terms of the homological pairings may also be of other types of relatedness, such as complementarity (as Greimas and Courtes stressed), but also a metaphorical one. In fact, given our previous focus on marketing metaphoria, homological pairings are particularly useful for chaining surface discourse terms with corresponding brand image attributes or nuclear semes. Such a metaphorical connectivity is also recognized by Rastier (1989).

Insofar as a brand's semic microunivesre consists in a set of image attributes (that reflect attributes and benefits linked both to direct product experience and intangible associations stemming from the metaphorical inscription of the brand's values), then brand image constitutes a brand's depth grammar. This is an important aspect that is lacking from recent structuralist semiotic accounts (i.e. Bianchi 2011) of the function of marcomms, which attempt to reconstruct the semic universe of surface discursive structures by reading the text backwards, albeit disregarding the motivational status of the text as intended brand master narrative, implying the preexistence of a semic microuniverse of which the ad filmic text is a manifestation. Such a unidirectional reading (i.e. top-down) risks not only missing out on the vexed issue of brand coherence, but of imposing a seemingly coherent structure that is completely incompatible with the brand owner's intentions (not to mention the probability of fit with the destinataire's decoding). In fact, this is another topos where communicative dissonance is likely to spring up as an outcome of the operation of reduction, viz. focusing on a set of surface stimuli and reducing them to binarist pairs. As Eco pointed out with regard to Greimas's analysis of the universe of Bernanos (cf. Greimas 1966, 222-224), «he undoubtedly brings to light the oppositions which can be found in the text on the level of a certain working hypothesis; but nothing prevents another reader, using that text in a different way, from singling out another key to reading and therefore of reducing it to different oppositional values» (Eco 1976, 83). This point is reiterated in the Philosophy of language as potentially 
conflicting readings of a text in terms of thematic isotopies: «Greimas has further stressed the possibility of conceiving of texts able to provide manifold and mutually contradictory isotopic interpretations» (Eco 1986, 192). Complementary to this considerable gap in the reading strategy, the aforementioned analysis is prodigiously obfuscated by the attribution of semic status to surface structure elements (man, woman) of the Camay print ad employed by Eco in his original analysis (Eco 1972). The aforementioned approach, which does offer a more expansive outlook in terms of the variety of modalities involved in brandcomms, even though in passing, is plagued by the same self-contained extrapolations that undergirded previous top-down reconstructive attempts (i.e. Floch 1985), that is without establishing a product categorical frame of reference. This is further augmented by reducing a brand's semic microuniverse to binarist structures, which did constitute Greimas's method of the logical arrangement of signification (i.e. semantic axis 1966, semiotic square 1970), but which have since been seriously challenged by connectionist approaches to the organization of signification in consumers' memory (which approach is favored by Eco in terms of opting for Quillian's model in Theory of Semiotics and the Role of the Reader and by Rastier 1989). «Semiosis, far from following tidy linear axes, may take place through networks» (Jensen 1995, 166). In fact, as attested by latest advances in consumer research pertaining to the mode of formation of brand knowledge structures and brand image, the organization of attributes and stimuli as sources of attributes is better accounted for through associative networks (i.e. Teichert and Schontag 2010), rather than binarist pairs. Indicatively I am citing the output of such an associative network from primary consumer research data stemming from a project that I handled personally in the past:

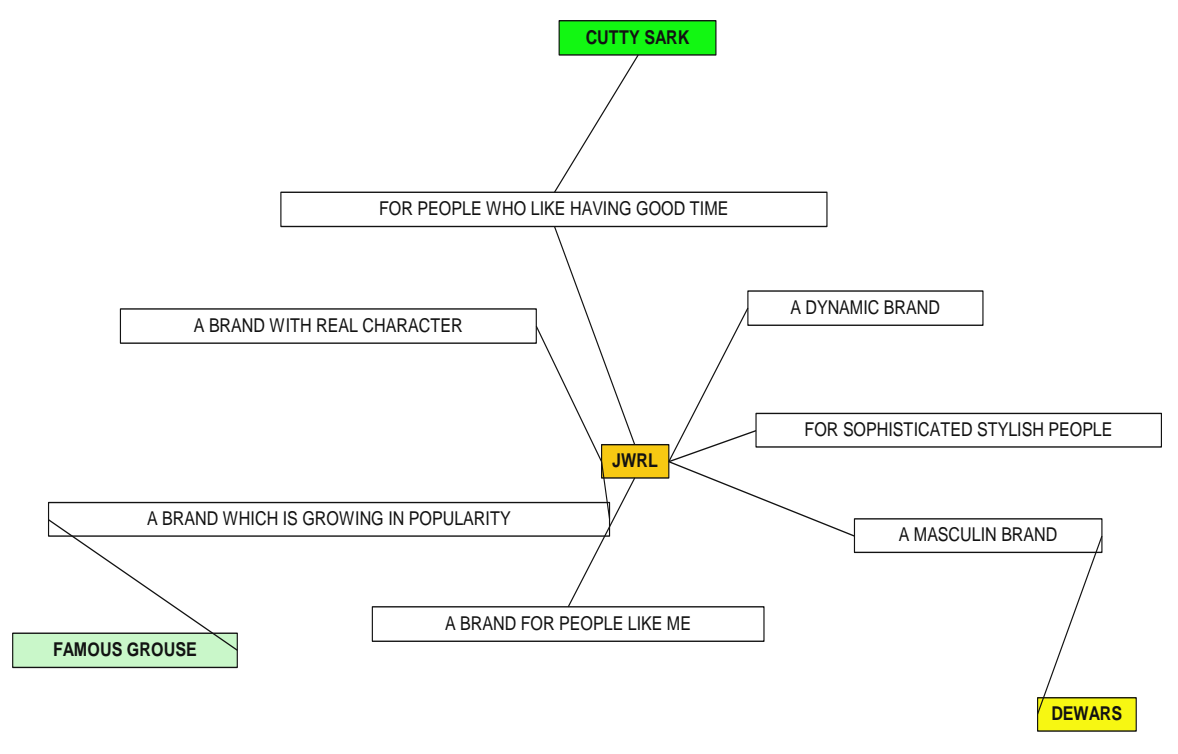

Figure 24: Example of quantitative research associative network from proprietary research in the alcoholic drinks market (identity of the client not disclosed for confidentiality reasons)

A similar rationale to the amply used associative networks in applied brand image research underpins Rastier's application of Sowa's conceptual graphs. «The nodes of these graphs are 
labelled after semantic units of all sorts (including semes, semic molecules and sememes). Their links are labelled after semantic primitives» (Rastier 1989: 61).

The above do not imply that binarist readings do not constitute useful heuristics in the exploration of tentative hypotheses ${ }^{10}$, «but in itself would not be enough» (Eco 1976, 94). However, claims regarding the value of binarist approaches to the organization of brand signification, such as «the binary analysis of cultural data provides a window onto the myths and archetypes that structure the collective unconscious» (Oswald 2012, 13), coupled with an unfortunate obfuscation of the constructionist underpinnings of structuralism with metaphysics and a complete absence of any coherent model of brand equity ${ }^{11}$, contrary to programmatic declarations, certainly do not constitute an advancement compared to traditional structuralist semiotic approaches, such as Floch's (2001) and Semprini's (1992),

The above-mentioned advances that resonate from a branding research point of view Eco's proclivity for using Model Q (cf. Eco 1976, 122-125) at the expense of a multiplicity of semiotic squares (which entails a cumbersome activity with doubtful results, given that interlocking squares may encapsulate a multiplicity of interpolated terms, but may not yield an outlook of the relative importance of semes as nodes in a network) and corroborate earlier assumptions by Keller $(2003 ; 2008)$ about the role of associative networks in portraying the organization of a brand knowledge structure in consumers' memory, point to definite directions for the formulation of structures of the énoncé during the encoding phase. This associative rationale also constitutes a fundamental building block in cutting edge research into the mode of formation of a brand langue and its storage in consumers' memory apparatus, as illustrated in Zaltman and Zaltman's Marketing Metaphoria (2008).

\section{Homological signifying chains as the starting point in brand image creation}

In order to illustrate the crucial operation of homologation let us assume as our interpretive substratum two highly impactful and awarded in terms of effectiveness commercials of the leading whiskey brand Johnnie Walker in Diageo's portfolio, viz. «Fish» (2003) ${ }^{12}$ and «Android» ${ }^{13}(2006)$.

\footnotetext{
${ }^{10}$ Both binarist and connectionist approaches are common currency in applied branding research.

${ }^{11}$ For a semiotic account of brand equity see Rossolatos $2012 \mathrm{c}$

${ }^{12}$ Accessible through http://www.youtube.com/watch?v=1NH35waex4s\&feature=related (downloaded 3/2/2012, 18:00 pm). See Appendix 1 for script.

${ }^{13}$ Accessible through http://www.youtube.com/watch?v=pcdSgS6EkDA\&feature=fvsr (downloaded 3/2/2012, 18:00 pm). See Appendix 1 for script.
} 


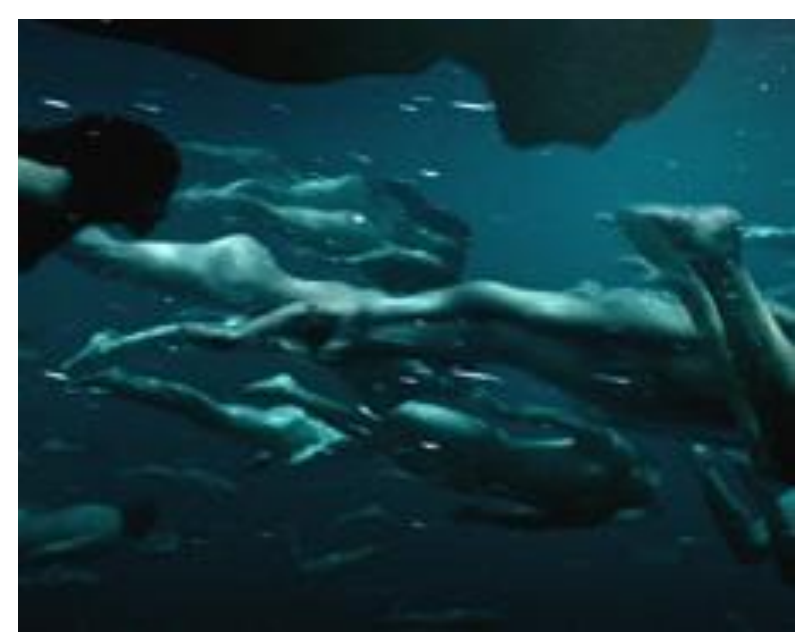

Picture 1: Frame from JW «Fish» TVC

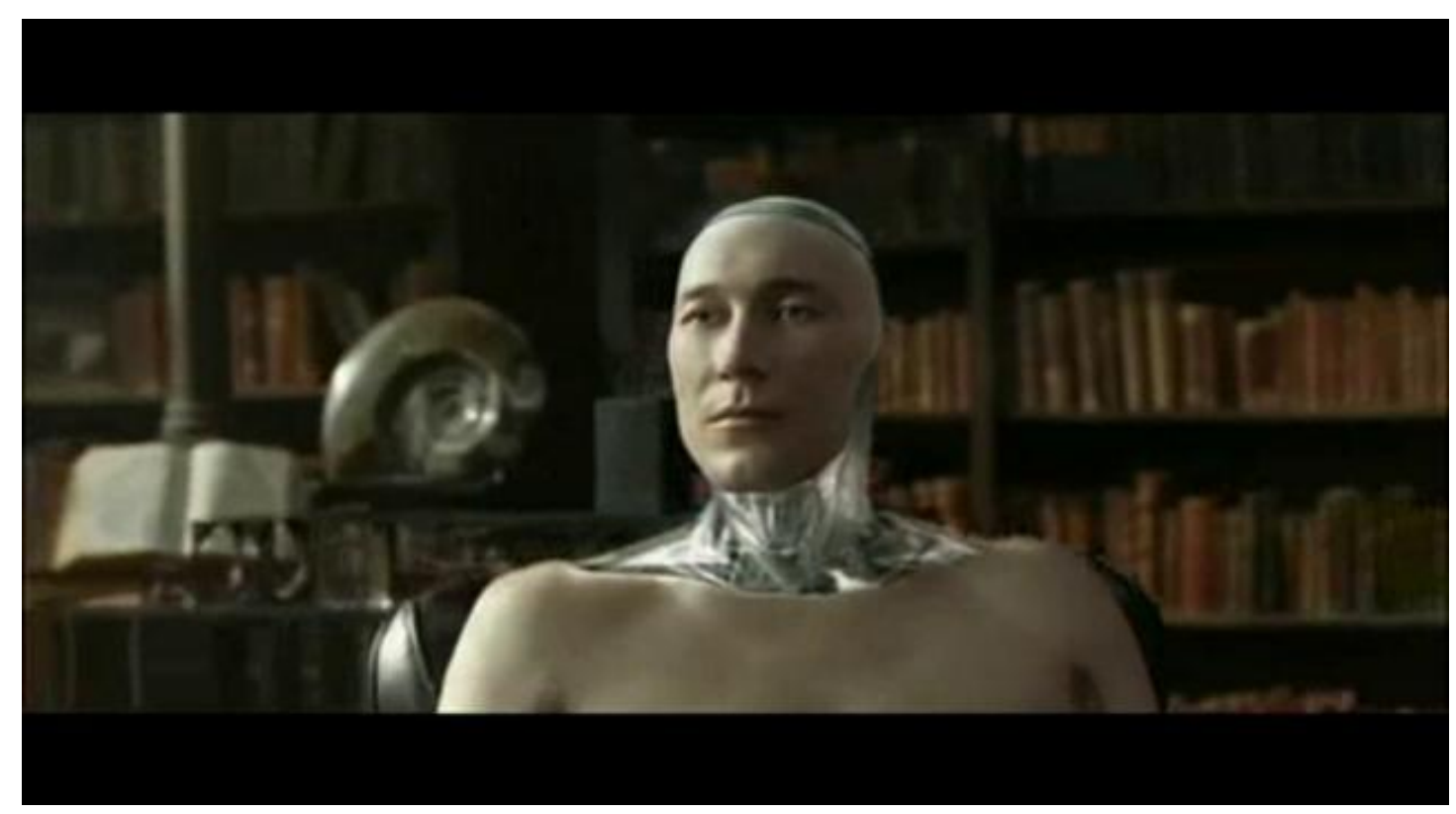

Picture 2: Frame from JW «Android » TVC

The first oppositional pair that springs to mind while attempting to reconstruct both films through the logical square (tentatively employed in the context of exploring hypotheses about homological relationships and not as the ultimate analytical tool as per section 6) is the one between /human/ and /non-human/, even though the semic universe making up the brand's core identity and periphery is certainly not exhausted in such an elementary pair.

In fact, this is a key threat embedded in the operation of reduction, viz. the non sufficiently discriminating and over-generic nature of the resulting pairs. Albeit, this elementary level of analysis suffices for the argumentative purposes of demonstrating the usefulness of homologation as a key operation in the process of constructing a brand's structuration through the employment of reduction and redundancy of its discursive structures. In the case of «Fish» the opposition is evinced in the form of /human/ vs /fish/, while in the case of «Android» the opposition is evinced in the form of /human/ vs /robot/. Now, these oppositions are posited as such in the context of the brand's elementary structure of signification, prior to being 
embedded as actants in the brand's master narrative that links elements of the depth structure (i.e. semes, classemes, sememes) with elements of the surface structure (lexemes, videmes or shots, sequences).

The top-down reconstruction takes place against the core positioning elements or nuclear semes of /savviness/ and /progress/ embedded in the brand's master narrative, which fuel motivationally the interpretive directionality of the brand's discursive manifestations. These elements of the brand's depth grammar should be kept in mind as the semiotic reconstruction proceeds along the strata of the generative trajectory of signification.

Homologies may be established between semes, sememes and key shots, wherein they are anchored, against the background of the acceptable scope of homologation as previously described. The resulting homological pairs and ultimately the homological chain that will consist of the stringing of these pairs is equivalent to an account of a brand's coherence, but also of how this coherence emerges through the maintenance of communicative consistency throughout various énoncés or expressive units.

In order to construct a homologation chain it is prudent to start by reducing elements of the surface structure through a semiotic square.

The semiotic square is a way of logically organizing the events of the plot of the surface structure or the brand's narrative program. Its key dimensions, as described in Section 3, consist of opposition, contrariety and implication ${ }^{14}$. Given that the square is a dynamic structure, it allows for mapping the transition of brand related meaning through its axes.

The bottom axis of the square constitutes the 'neither/nor' or 'neutral zone', where brand meaning partakes of neither of the opposites of the key terms of the initial pair of contrariety.

In our example, the neutral axis consists of the semantic relationships between /nonhuman/;/non-fish/ and /non-human/;/non-android/ for the two commercials respectively. Let us point out that we are still situated interpretively in the first stage of the reconstruction of the brand's signification, while simply translating images into lexemes (the image of fish into the word fish), while not making any statements about the relationship between surface structure lexemes with more abstract image associations as part of the brand's semantic nucleus.

At this primary level of analysis it is feasible to describe the brand's enunciative structure as the progressive transformation among states of being, which constitute movements around the square. The énoncé is split into three stages, each one of which constitutes a separate transition phase in the communication of the semic structure as master brand narrative from destinateur to destinataire. Let us recall that the reconstruction of the brand's semantic transformation as passage through identifiable states of being does not consist in a reflection of the linear sequencing of the manifest plot's structure, but to its opening up to virtual

\footnotetext{
${ }^{14}$ For a more analytical outlook of the dimensions of the square see Rossolatos $2012 \mathrm{a}$
} 
possibilities of becoming. But in the case of the filmic texts at hand, the noted transitional phases are inscribed in the discursive surface.

At the primary level of analysis the phases in the transition amongst the three stages of becoming as movements in the respective axes of the square for each of the two films consist in (A1) (i) the initial co-existence of /fish/ and /human/ as non-identifiable species, (ii) manifested through shots such as humans swimming underwater like fish and a close-up to a human/fish's genitalia manifesting absence through shading, which gives its place (A2) (i) to a relationship of contrariety between /fish/ and $/ \mathrm{man} /$, (ii) evinced at the surface structure in the sequence bridging the shots of being underwater and being on the coast, which results in (A3) (i) a clear opposition between fish and man, as relationships between /man/ and /non$\mathrm{man} / \mathrm{and} / \mathrm{fish} /$ and /non-fish/, also united by relationships of implication between $/ \mathrm{man} / \mathrm{and}$ /non-fish/ and the inverse pair, (ii) as evinced by the opposition between walking on the coast on both feet, as against swimming in a fish-like fashion underwater. In the case of the «Android» the respective dimensions, phases and corresponding textual elements may be rendered as a passage from (B1) (i) an initially clear opposition between /android/ and /human/, (ii) as evinced in the android's monologue «I'm faster than you, stronger than you, etc» to (B2) (i) a state of co-existence, or the robot's contemplating what is like to be human, (ii) «to love, to despair», culminating in (B3) (i) a relationship of contrariety, (ii) as evinced by the invitation of the android to the human to become immortal by keep walking.

Based on the above reconstruction of the basic relationships between transitional phases in the brand's énoncé and the shots/sequences whereby they are discursively manifested we may draw an initial chain of homologation in the following form: (A1)i:(A1)ii::(B2)i:(B2)ii, which may also be read in the brand's langue as to be neither human nor fish nor android is like emerging from underwater living to the coast and loving/despairing/hoping, (A2)i:(A2)ii::(B3)i:(B3)ii, which may be read as a human's being contrary to either a fish or android is like «keeping walking» as a transition from underwater being or an android to a struggling human and (A3)i(A3)ii::(B1)i:(B1)ii, which may be read as a human's being in a relationship of opposition to either fish or android is like walking on both feet on a coast or not being as fast and strong as an android.

These homologations are crucial for the production of brand signification through its manifest discourse and the discernment of a brand related canonical narrative schema. The underpinning of a brand specific canonical narrative schema consists of recurrent themes ${ }^{15}$ through variable ad executions. Through recurrence as a manifestation of communicative consistency brand coherence is maintained.

\footnotetext{
15 Rastier (1989: 55) defines generic themes as «semantic classes that are manifested in the text through the recurrence of their members». He draws a sharper distinction between three semantic classes to which correspond three general themes (ibid: 55-56). The taxeme is the minimal class wherein sememes are interdefined, for example cigarette, cigar and pipe are opposed to each other at the level of the taxeme //tobacco//. Domain is a more general class that includes various taxemes. Dimension is a class of even greater generality; It comprises oppositions such as //animate// vs //inanimate//. The recurrence of a generic theme is tantamount to the establishment of an isotopy.
} 


\section{Brand image creation as a function of isotopies against the background of intra-brand diachronic communication}

Further to the construction of homological chains let us now proceed with identifying (i) an isotopically recurrent theme, where «theme», following Metz (1971, 503;513), is conceived as the depth structure of a film, between the two films as an inter-filmic homology between surface structure shots/sequences and a nuclear seme as core image attribute of Johnnie Walker's signifying kernel or semantic microuniverse (ii) a pluri-isotopy ${ }^{16}$ as two recurrent themes on an intra-filmic level through the establishment of a chain of homologation (and the analysis may be expanded both intensively and extensively). Thus, assuming the same classification of surface structure shots/sequences as previously demarcated, and denoting as the isotopically recurring nuclear seme of /progress/ (which is assumed to be intended as such during the encoding of the filmic text by the brand owner as a projected user personality trait that reflects back on the brand as a brand personality image attribute) in both films as (A4) for 'Fish' and (B4) for 'Android', we may discern the following inter-filmic homology: (A2)ii:(A4)::(B3)ii:(B4). This homology accomplishes task (i). Task (ii) may be accomplished by assuming, this time in the context of the 'Android' a pluri-isotopy, in the form of the nuclear seme of /progress/ functioning in complementarity with the seme /savviness/. /Savviness/ is translated parasynonymically as brand savviness connoting expertise, for example, in the distillation process, involving the right balance in the blend of ingredients, the distillation period and natural conditions etc., which reflects back on the consumer, who is instituted by implication in the brand's discourse as /savvy/ who opts for a safe, credible, tried and tested brand choice. /Progress/ recurs isotopically in at least two instances, first in the aforementioned (B3)ii, which constitutes a verbal syntagm or a performative utterance in the imperative mode in the filmic unity and second in the key visual of the android that stands aliquid pro aliquo for progress per se, which may be denoted as (B5)ii. Insofar as both (B3)ii and (B5)ii concern the level of form of expression, they may be classified as one expressive unit (B3ii, B5ii).

/Savviness/ recurs isotopically in at least two instances in the ad filmic text, in the sign of the library embedded in the opening shot featuring the contemplating android (B6)ii and in the context of his self-proclaimed attribute of immortality (B7ii), in which the divine attribute of omniscience is engrafted by definition (perhaps enabled by the co-presence of B6ii as immortality might simply be an instance of pure materiality without evoking any cognitive aspects). This expressive unit may be classified as (B6ii, B7ii).

Pursuant to the above the pluri-isotopy in the Android film may be recognised through the homologation (B3ii,B5ii):/progress/::(B6ii,B7ii):/savviness/.

\footnotetext{
${ }^{16}$ Rastier redefined the term as poly-isotopy, while retaining the same operative meaning (Rastier 1989: 280).
} 


\section{How do brand image attributes morph in the light of narrative and discursive structures?}

Based on the preceding analysis, brand image attributes are equivalent to figures. They have a relatively stable meaning, which varies according to different ad textual contents. Based on the selected example of JW ads, the isotopically emergent brand image attributes or nuclear semes from the two commercials are /saviness/ and /progress/. The way these image attributes function as recurrent elements of JW's brand identity structure, and yet differ in terms of their contextual semantic investment may be portrayed as follows:

\begin{tabular}{|c|c|c|}
\hline & Stable meaning & Contextual variation \\
\hline $\begin{array}{l}\text { Nuclear seme } \\
\text { /saviness/ }\end{array}$ & $\begin{array}{l}\text { Brand personality: } \\
\text { Know-how in production } \\
\text { process }\end{array}$ & $\begin{array}{l}\text { Fish: Knows the secret of } \\
\text { evolution. } \\
\text { Android: Omniscience }\end{array}$ \\
\hline $\begin{array}{l}\text { Nuclear seme } \\
\text { /progress/ }\end{array}$ & $\begin{array}{l}\text { Brand personality: A } \\
\text { constantly evolving brand } \\
\text { User personality: } \\
\text { Someone who constantly } \\
\text { seeks to overcome his self, } \\
\text { reach for maximum } \\
\text { potential }\end{array}$ & $\begin{array}{l}\text { Fish: Evolution of the species } \\
\text { as myth of origin } \\
\text { Android: The end of } \\
\text { evolution of the species }\end{array}$ \\
\hline
\end{tabular}

Table 2: Brand image attributes as recurrent nuclear semes through differential contextual semantic investment

Thus, the master brand narrative of JW involves the brand as the key actant (while refraining from using Proppian narrative typologies, such as 'hero' and 'helper') who, at the semionarrative level, is responsible for maintaining a canonical narrative schema. The canonical narrative schema concerns the textual institution of a set of background expectations about the brand. These expectations concern an anticipatory structure on behalf of the target audience as a recurrent depth structure in terms of nuclear image attributes or the nuclear semes of /savviness/ and /progress/. Even though I had no direct access to Diageo's internal brand planning documents prior to the top-down reconstruction of the brand's generative trajectory of signification, published information about the brand's positioning confirms that these two nuclear semes actually constitute the brand's core positioning, especially among the core target group of males 25-34 yrs. old ${ }^{17}$. These core image attributes of JW are operative in the 
brand's depth structure (at least during the period when the concerned ad executions were aired).

On a surface discursive level these recurrent nuclear semes are evinced differentially as contextually enriched semes or sememes, either through the visual of an omniscient robot or through a filmic sequence suggesting that the brand knows the secret of evolution. By the same token, the recurrent image attribute of /progress/ is contextually evinced either through the discourse of an android who stands for the end of progress or through a filmic sequence that portrays the evolution of the species. The maintenance of brand coherence as recurrent nuclear brand image attributes is effected by rendering redundant contextual elements that are not pertinent in terms of the brand's canonical narrative schema, such as the visual of the butterfly in the Android TVC or the visual of the sphere in the Fish TVC, thus reducing meaning to its bare essentials, that is to the invariant elements of brand signification. This process represents structuration and the way whereby a brand's semantic micro-universe and positioning is maintained diachronically throughout variable ad executions.

It is important to note that what functions figuratively in the surface brand discourse is not the visual signifier, but the nuclear seme. Contrary to what is standardly theorised in visual semiotics as figurative discourse, that is incumbent on the visual sign, what is primarily figurative in branding language is the nuclear seme as abstract concept or element of the form of the plane of content. As Giroud and Panier (1975) argue, the figure is envisaged from the point of view of virtuality. A core brand image attribute or nuclear seme, by virtue of its being part of a motivated sign system constitutes a virtual space that may be semantically invested in contextually variable ways. This is not the same as the distinction between denotation and connotation. A brand sign system is metaphorological in essence, hence the figurative nature of a nuclear seme. The stability of the meaning of an image attribute as recurrent brand identity backdrop is not equivalent to the denotative plane of a brand's langue, but to a relative degree zero of signification, as conceptualized by Groupe $\mu$ (1992). The general degree zero is furnished by the prior knowledge of a code that links elements of a manifest text (irrespective of modality). The local degree zero is furnished by the isotopy of an énoncé. Groupe $\mu$ uses the term isotopy in a Greimasian sense, as the grounding of an idea in a totality of meaning or an entire text. The local degree zero is the element pertaining to such a territory of an énoncé, by virtue of a structure that is particular to that énoncé. This is the case where visual plastic énoncés engender internal regularities. They also stress explicitly that isotopy is a very useful concept, especially for advertising, among other discourses, which are characterised by polysemy and interpretive openness.

Contextual variations as distantiations from this relative degree zero constitute deflections of a brand's internal structure or mirroring effects of a logico-semantic simulacrum. By virtue of brand image attributes' ability to be fleshed out in different narrative programs or TVCs

\footnotetext{
17 See Elen Lewis, Walking the wiser walk, Brand Strategy, September 2005; Steve Mustarde, Johnnie Walker: The story behind keep walking, Campaign Nov. 2008; JW case study (http://marketing-casestudies.blogspot.com/2008/07/keep-walking-campaign.html); JW PR case study (http://www2.prnewswire.co.uk/cgi/news/release?id=189933)
} 
against a master brand narrative, they constitute what Girou and Panier call «discursive configurations» (1975: 95). The inventory of possible discursive configurations amounts to a brand's discursive dictionary. "The discursive dictionary may be presented as a stock of themes and patterns» (ibid: 96). According to Eco (1976) isotopies do not occur simply at the thematic level or, in our instance, at the level of a semic nuclear structure, but also at the level of surface discourse elements, which he calls stylistic isotopies. Thus, a brand's dictionary includes not only its core image attributes, but also contextually enriching elements. Contextual brand elements (i.e. the visual of the butterfly in the aforementioned JW android film) attain to enrich a brand's narrative structure, but, as already noted, only to the extent that they do not compromise the integrity of either uniformly recurring surface discourse elements or the underlying image structure.

\section{Conclusions}

The main purpose of this paper was to add to the existing structuralist semiotic branding research by showing how key operations in the trajectory of signification function in a way that integrates brand signification throughout the semiotic strata. The underlying objective was to demonstrate how a brand maintains its structural coherence and communicative consistency as recurring brand image nucleus throughout variable ad executions. This approach may be enriched and extended by bringing into play a competitive outlook. The process of structuration and the involved operations of recurrence, redundancy, reduction, homology and isotopy, as defined by Greimas and Courtes and enriched conceptually by structuralist semiotic thinkers, such as Eco and Rastier, were recruited to this end.

The issues of brand coherence and communicative consistency constitute time-hallowed concepts in the marketing literature. Through a constructive dialogue with branding models that have been formulated within the marketing discipline, structuralist semiotics may yield conceptual and methodological frameworks for building and maintaining brand image over time. 


\section{Appendix 1- Johnnie Walker TVC scripts}

\section{Johnnie Walker «Fish» commercial script}

\section{( http://www.framestore.com/\#/Commercials\%20London/JohnnieWalker,Fish )}

Fish starts with the camera moving over the surface of a blue-green ocean. It submerges and we catch our first glimpses of what appear to be multitudes of shoaling fish. The images are familiar from nature documentaries - the 'fish' darting in different directions, the many acting as one, the shoal seeming almost an entity in itself. As the camera closes in on the shoal, we realise that the creatures we are seeing are not fish but people - arms by their sides, legs together - driving themselves through the water with great speed and grace.

The pace picks up as we see the people near the surface, and then they start to leap out of the water. From above we see not one or two, but many, many men and women shooting out of the water like dolphins playfully racing each other. It is exhilarating and impossible. We finally return under the water, now in the shallows. One of the men touches his foot down onto the white sand. He stands up. He walks forward onto the beach of a tree-lined bay, others emerging to follow him. As he moves purposefully inland, we fade to black and the slogan 'Keep Walking'. This brief description of the action of the spot barely does justice to the beauty and power of the images - you really do have to see it to get it.

\section{Johnnie Walker «Android» commercial script \\ (http://lemonsblack.com/johnny-walker-human/ )}

An android sits in a library in a futuristic setting utters "I am faster than you, stronger than you. Certainly I will last much longer than you. You may think that I am the future. But you're wrong. You are. If I had a wish, I'd wish to be human". Outside now, the android turns in the sunlight. "To know how it feels to feel". The android grabs a butterfly in his hand, then releases it.Back in the library the butterfly provides a point of continuity for the soliloquy. "To hope, to despair, to wonder, to love. I can achieve immortality by not wearing out».

"You can achieve immortality simply by doing one great thing " - Keep walking

\section{References}

Aaker, David (1991). Managing brand equity: Capitalizing on the value of a brand name. New York: Free Press (mobipocket edition).

Aaker, David (1996). Building strong brands. New York: Free Press.

Alexander, Monty (1996). The myth at the heart of the brand: Successful brands embody myths- now they can be analysed. Esomar Congress paper.

Barthes, Roland (1968). Elements of semiology. New York: Hill and Wang.

Barthes, Roland (1974). S/Z. New York: Hill and Wang.

Barthes, Roland (1977). Image-Music-Text. London: Fontana. 
Bianchi, Cinzia (2011). Semiotic approaches to advertising texts and strategies: Narrative, passion, marketing. Semiotica, 183 (1/4), pp.243-271.

Birdwell, Al E. (1968). A Study of the Influence of Image Congruence on Consumer Choice. The Journal of Business, (41)1, pp.76-88.

Buckland, Warren (2004). The cognitive semiotics of film. Cambridge: Cambridge University Press.

Cavassilas, Marina (2009). Le fun se joue des valeurs. Emballages. (www.emballagesmagazine.com )

Cossette, Claude (1973). Vers une grammaire de l'image publicitaire. Communication et langages 19, pp.93-105.

Courtés, Joseph (1976). Introduction à la sémiotique narrative et discursive. Paris: Hachette.

Dahlen, Michael, Lange, Frederik and Smith, Terry (2010). Marketing communications: A brand narrative approach. Sussex: Wiley.

Danesi, Marcel (1995). Interpreting advertisements: A semiotic guide. New York: Legas.

Danesi, Marcel and Beasley, Ron (2002). Persuasive signs: The semiotics of advertising. Berlin: Mouton.

Danesi, Marcel (2006). Brands. London: Routledge.

Danesi, Marcel (2007). The quest for meaning: A guide to semiotic theory and practice. Toronto: University of Toronto Press.

De Chernatony, Leslie (2006). From Brand Vision to Brand Evaluation: The strategic process of growing and strengthening a brand. Oxford: Butterworth-Heinemann.

De Chernatony, Leslie and McDonald, Malcolm (2003). Creating powerful brands in consumer, service and industrial markets. Oxford: Butterworth-Heinemann.

Eco, Umberto (1972). La Structure Absente, Paris: Mercure.

Eco, Umberto (1976).Theory of Semiotics. Bloomington, Indianapolis: Indiana University Press.

Eco, Umberto (1986). Semiotics and the philosophy of language. Bloomington, Indianapolis: Indiana University Press.

Elliott, Richard and Ritson, Mark (1995). A model of advertising literacy: The praxiology and co-creation of advertising meaning. Proceedings of the 24th Conference of the European Marketing Academy, 
Evans, Malcolm and Harvey, Michael (1998). Cracking the Code. Research magazine Nov. Issue.

Evans, Malcolm (1999). Semiotics, culture and communications: The common-sense of the 21 st C. Proceedings of the Australian Market Research Society Conference.

Evans, Malcolm and Harvey, Michael (2001).Decoding competitive propositions: A semiotic alternative to traditional advertising research. Market Research Society 43 (2), pp. 171-187

Floch, Jean-Marie (1988). The contribution of structural semiotics for the design of a hypermarket. International Journal of Research in Marketing, 4 (3), pp. 233-52.

Floch, Jean-Marie (1989).The semiotics of the plastic arts and the language of advertising, In Paris school semiotics II, Paul Perron and Frank Collins (eds.). The Netherlands: Jon Benjamin.

Floch, Jean-Marie (2000). Visual Identities. London: Continuum.

Floch, Jean-Marie (2001). Semiotics, Marketing and Communication. London: Palgrave Macmillan.

Giroud, Jean-Claude and Panier, Louis (Groupe d' Entrevernes) (1979). Analyse sémiotique des textes. Lyon: Presses universitaires de Lyon.

Greimas, Algirdas J.(1966). Sémantique structurale. Paris: Presses universitaires de France.

Greimas, Algirdas J.(1970). Du sens I. Paris: Seuil.

Greimas, Algirdas J.(1971). Narrative Grammar: Units and levels, Modern Language Notes 86(6), pp.793-806.

Greimas, Algirdas J. and Courtés Joseph (1976). The cognitive dimension of narrative discourse. New Literary History 7 (3), pp.433-447.

Greimas, Algirdas J. and Joseph Courtés (1979). Sémiotique: Dictionnaire raisonné de la théorie du langage. Paris: Hachette.

Greimas, Algirdas J.(1983). Du sens II. Paris: Seuil

Greimas, Algirdas J.(1987). On Meaning. Minneapolis: University of Minnesota Press.

Greimas, Algirdas J. (1989 a). Description and narrativity: the piece of string. New Literary History 20 (3) (special issue on Greimasian semiotics),pp.615-626.

Greimas, Algirdas J. (1989 b). On meaning, New Literary History 20 (3) (special issue on Greimasian semiotics), pp.539-550.

Greimas, Algirdas J., Collins, Frank, Perron, Paul (1989 c). The veridiction contract. New Literary History, .20 (3) (special issue on Greimasian semiotics), pp.651-660.

Greimas, Algirdas J., (1989 d), Figurative semiotics and the semiotics of the plastic arts. New Literary History.20 (3) (special issue on Greimasian semiotics), pp.627-649. 
Greimas, Algirdas J. and Courtés, Joseph. (2003). Basic concepts of Greimasian semiotics. In Semiotics Vol. I, Mark Gottdiener, Karin Boklund-Lagopoulou and Alexandros Lagopoulos (eds.). London: Sage

Greimas, Algirdas J.(2003). Elements of a narrative grammar. In Semiotics Vol. III, Mark Gottdiener, Karin Boklund-Lagopoulou and Alexandros Lagopoulos (eds.). London: Sage.

Groupe $\mu$ (J. Dubois, F. Edeline, J.M. Klinkenberg, P. Minguet, F. Pire, H.Trinon, Centre d'études poetiques, Université de Liege) (1970). Rhétorique générale. Paris: Larousse.

Groupe $\mu$ (1992). Traité du signe visuel: Pour une rhétorique de l'ímage, Paris: Seuil.

Hebert, Louis (2011). Tools for text and image analysis: An Introduction to applied semiotics. www.signosemio.com

Hetzel, Patrick and Marion, Gilles (2000). Les contributions françaises de la sémiotique au marketing et à la publicité. Revue Gestion 3, pp. 117-154.

Hetzel, Patrick (2002). Planète Conso: Marketing expérientiel et nouveaux univers de consommation. Paris: Editions d'Organisation.

Hjelmslev, Louis (1969). Prolegomena to a theory of language. London: University of Wisconcin Press

Hjelmslev, Louis (1975). Resumé of a theory of language. London: University of Wisconcin Press.

Hollis, Nigel, Farr, Andy, Dyson, Nigel (1996). Understanding, measuring and using brand equity. Journal of Advertising Research, 36 (6), 9-21.

Hollis, Nigel, Farr, Andy, Dyson, Nigel (2009). Brand dynamics pyramid. European Institute for Brand Management.

Hollis, Nigel (2008). The global brand: How to create and develop lasting brand value in the world market. New York: Palgrave-Macmillan.

Jakobson, Roman (1985). Closing statement: Linguistics and poetics. In Semiotics: An introductory anthology, Robert Innis (ed.). Bloomington, Indianapolis: Indiana University Press.

Jensen, Klaus B. (1995). The social semiotics of mass communication. London: Sage.

Kapferer, Jean-Noel (2008). The new strategic brand management: Creating and sustaining brand equity long-term. London: Kogan Page.

Keller, Kevin L. (2003). Brand synthesis: The multidimensionality of brand knowledge. Journal of Consumer Research 29, pp.595-600. 
Keller, Kevin L. and Lehmann, Donald, R. (2006). Brands and branding: Research findings and future priorities. Marketing Science 25 (6), pp.740-759

Keller, Kevin L. (2008). Strategic brand management: Building, measuring, and managing brand equity. Upper Saddle River, New Jersey: Prentice-Hall.

Kotler, Philip and Keller, Kevin, K. (2006). Marketing management. New Jersey: PrenticeHall.

Light, Larry and Kiddon, Joan (2009). Six rules for brand revitalization: Learn how companies like McDonald's can reenergize their brands. Upper Saddle River, New Jersey: Wharton.

Metz, Christian (1971). Propositions methodologiques pour l'analyse du film. In Essays in semiotics, Julia Kristeva, Josette Rey-Debove, Donna J. Umiker (eds.), pp. 502-515. Berlin: Mouton.

Metz, Christian (1982). The Imaginary Signifier. London: Macmillan..

Mick, David G., Burroughs, James E., Hetzel, Patrick, Yoko Brannen, Mary (2004). Pursuing the meaning of meaning in the commercial world: An international review of marketing and consumer research founded on semiotics. Semiotica 152 (1 / 4), pp.1-74.

Parker, Brian T. (2009), A comparison of brand personality and brand user-imagery congruence. Journal of Consumer Marketing, (26) 3, pp.175-184.

Pasquier, Martial (1999). Marketing et sémiotique: Une approche interdisciplinaire. Fribourg: Editions Universitaires de Fribourg.

Pasquier, Martial (2005). Signe et signification des discours de marketing. Working paper, IDHEAP.

Péninou, Georges (1966), Réflexions sémiologiques et création publicitaire II: Eléments de method. Revue Française du Marketing 21.

Rastier, François (1989). Sens et textualité. Paris: Hachette.

Rastier, François (2003). De la signification au sens. Pour une sémiotique sans ontologie. http://www.revue-texto.net/Inedits/Rastier/Rastier_Semiotique-ontologie.html

Ricoeur, Paul (1989). Greimas' narrative grammar, New Literary History 20:3, pp.581-608.

Ries, Al and Trout, Jack (2000). Positioning: The battle for your mind. New York: McGrawHill.

Ries, Al and Ries, Laura (2002). The 22 immutable laws of branding. New York: Harper Collins. 
Rossolatos, George (2012a). Applications, implications and limitations of the semiotic square for analyzing advertising discourse and discerning alternative brand futures. Signs, An international journal of semiotics Vol. 6, pp.1-48.

Rossolatos, George (2012b). Repressenting the manimal: A semiotic/psychoanalytic approach to the strategic importance of anthropomorphism in branding. (http://papers.ssrn.com/sol3/papers.cfm?abstract_id=1999716)

Rossolatos, George (2012c). Towards a semiotics of brand equity: On the interdependency of meaning surplus and surplus value in a political economy of brands. Journal of Chinese semiotic studies, 2012 (1).

Saussure, Ferdinand de (1959). Course in General Linguistics. New York: Philosophical Library.

Semprini, Andrea (1992). Le marketing de la marque: Approche sémiotique, Paris: Liaisons.

Shairi, Hamid Reza and Tajbakhsh (2010). Narrative et tensivité dans le discours publicitaire de Cillit Bang. Revue de la faculté des lettres et sciences humaines, Annee 53, N.218 (no page numbering)

Sirgy, Joseph M. (1982). Self-concept in consumer behavior: A critical review. The Journal of Consumer Research, (9) 3, pp.287-300.

Solomon, Michael, Bamossy, Gary, Askegaard, Soren, Hogg, Margaret K. (2006). Consumer behavior: A European perspective. London: Prentice-Hall.

Sonesson, Goran (2011). Lecture 4: From the Linguistic Model to Semiotic Ecology: Structure and Indexicality in Pictures and in the Perceptual World. Lecture notes from IAAS seminar on pictorial semiotics.

Teichert, Thornsten A. and Schontag, Katja (2010). Exploring consumer knowledge structures using associative network analysis, Psychology and Marketing 27(4), pp.369-398.

Trout, Jack (2010). Repositioning: Marketing in an era of competition, change and crisis. New York: McGraw Hill.

Zaltman, Gerald and Zaltman, Lindsay, H. (2008). Marketing metaphoria: What seven deep metaphors reveal about the minds of consumers. Boston, Massachusetts: Harvard Business Press.

Valentine, Virginia (2001). Repositioning research: A new MR language Mmdel. Market Research Society conference proceedings. 